
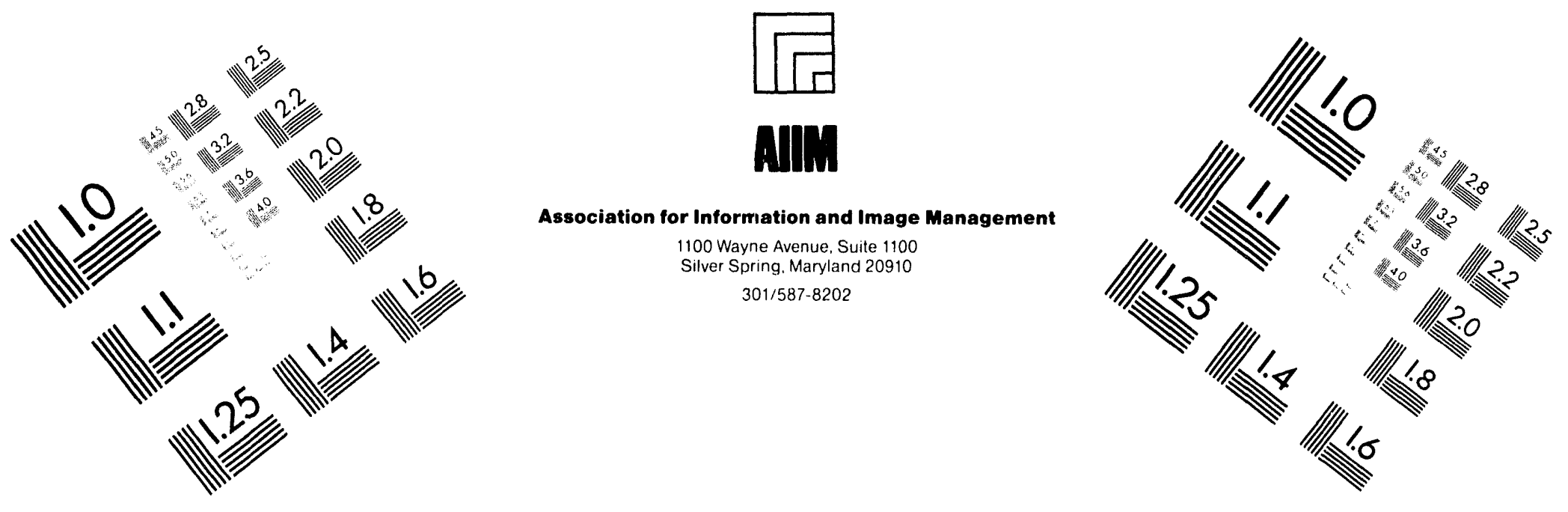

\title{
Centimeter
}

Thلس

Inches
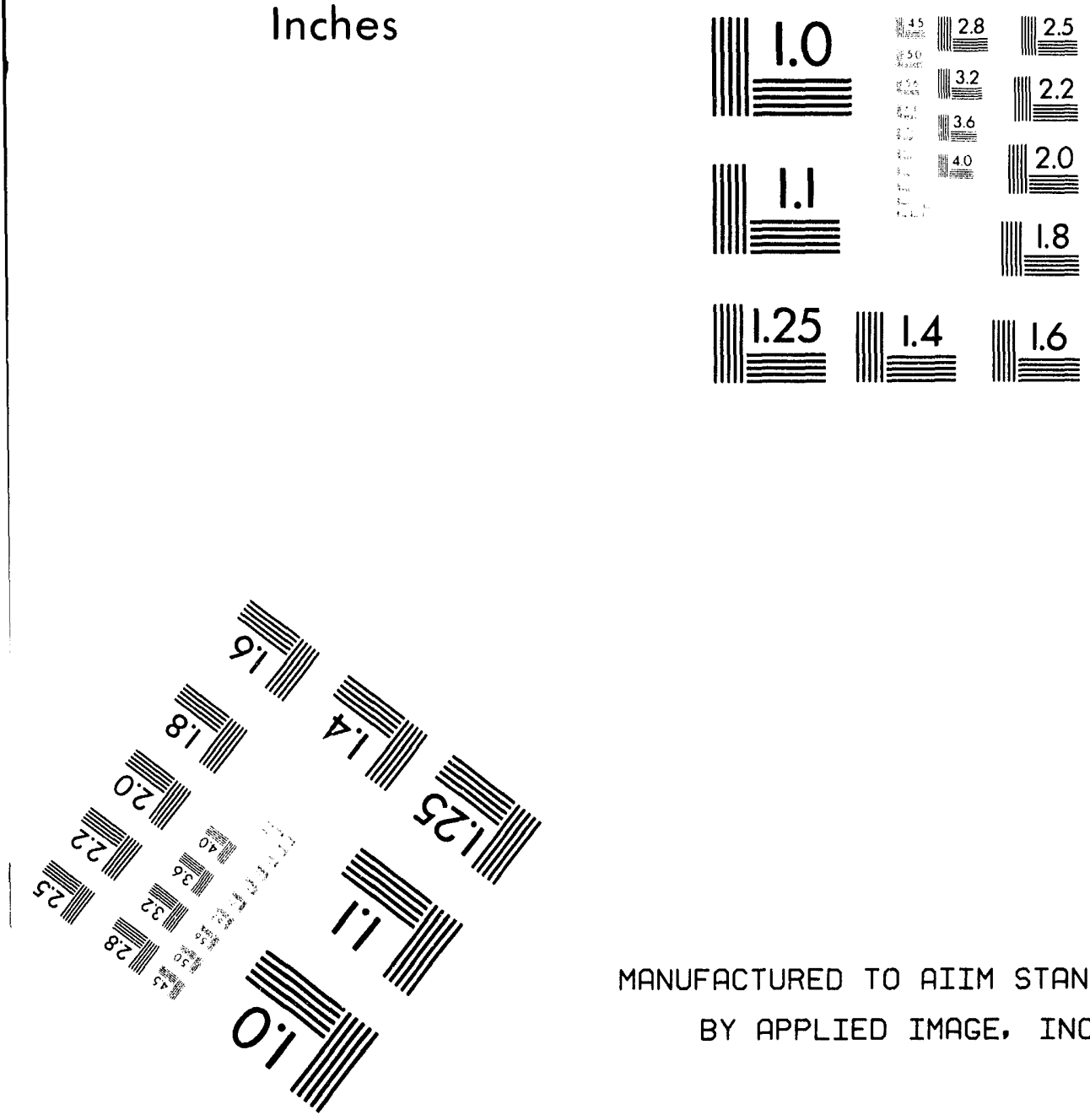

MANUFACTURED TO AIIM STANDARDS

BY APPLIED IMAGE, INC.

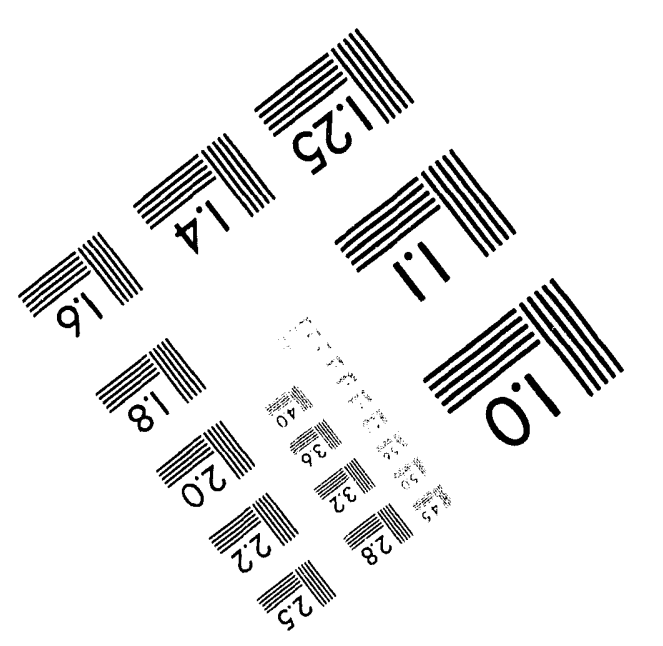



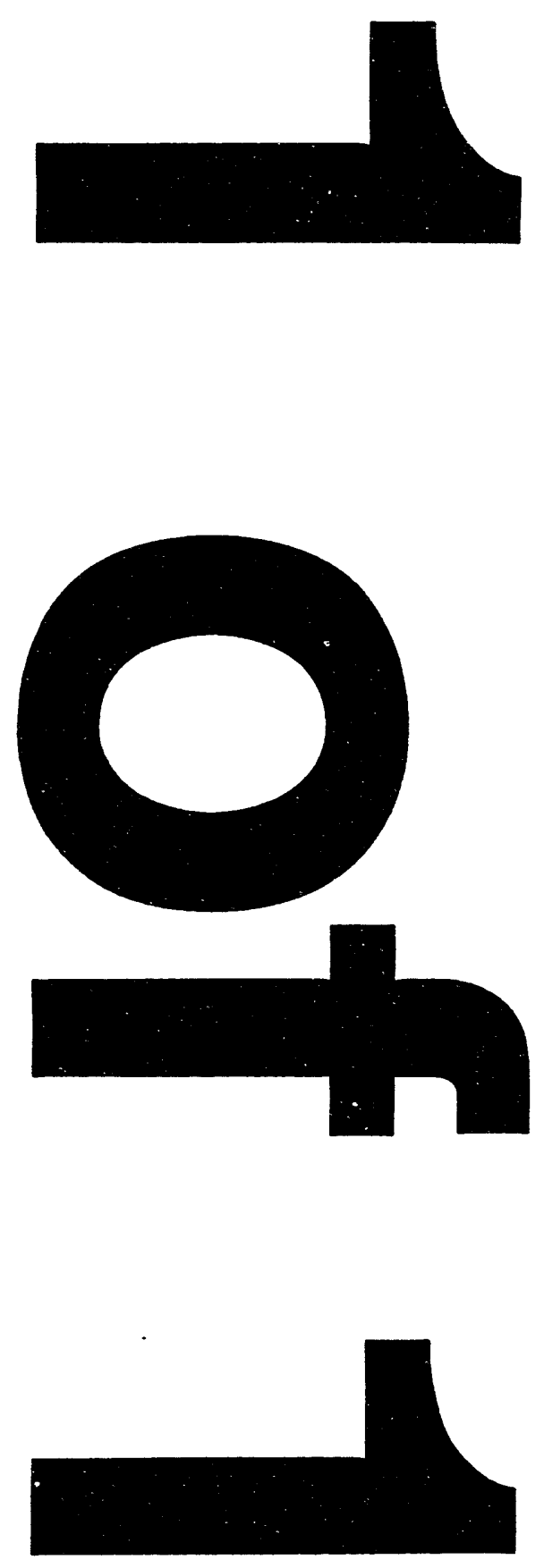


\section{Interpretation of Seismic Reflection Data from the Piledriver Event Area, Nevada Test Site; \\ A Case Study for \\ Evaluation of Technique for Characterization of Void and Chimney Features.}

Submitted in partial fulfillment of the requirements for a Masters of Science degree in Mineral Engineering

Prepared by:

Karl E. Tonander

Department of Mineral and Environmental Engineering New Mexico Institute of Mining and Technology

Socorro, New Mexico

Spring, 1993 


\section{Acknowledgment}

I wish to thank the Geophysics Group (EES-3) of Los Alamos National Laboratory under the direction of C.L. Edwards for their help in gathering the data and financial support for much of the reduction and writing. I also wish to personally thank my instructors in the Mining Department for their help with my education and support over the years. Finally, I would like to thank my parents, without whose encouragement I would have never undertaken a college program such as this. 


\begin{abstract}
A remote sensing geophysical method is needed to properly characterize the void and chimney characteristics of underground nuclear tests. Various techniques were considered and a seismic reflection survey was selected. This survey was then fitted to the conditions at the test site so as to give optimum results. The data was then reduced via DOS computer and analyzed for content. The planned survey using a $50 \mathrm{ft}$ offset did not show any useful information, however, a second survey with a variable longer offset was also conducted which was capable of determining the depth to the top and the bottom of the chimney with reasonable accuracy. Measurements of the horizontal spread of the structure, though, were inconclusive.
\end{abstract}




\section{Table of Contents}

\subsection{INTRODUCTION}

1.1 Goals

1.2 Choosing the Appropriate Method

1.3 Components of Seismic Surveys

2.0 FIELD DATA ACQUISITION

2.1 Introduction to Field Methods

2.2 Hazards

2.3 Limitations

2.4 Spacing

2.5 Recording Parameters

3.0 DATA ANALYSIS

3.1 Processing

4.0 RESULTS AND CONCLUSIONS

4.1 Results

4.2 Conclusions

4.3 Recommendations

REFERENCES

BIBLIOGRAFHY

APPENDIX 


\section{List of Figures}

1. Piledriver Event Diagram 2

2. Relative Amplitudes of Various Projectile Sources 10

3. Elastic Wave Generator Diagram 14

4. Relative Amplitudes of an Elastic Wave Generator vs. Projectile Sources $\quad 15$

5. Geophone Diagram 16

6. Demonstrated Increase in Signal-to-Noise Ratio via Covering 19

7. A Typical Flow Path for Signal in a Digital Reflection Seismograph 20

8. Vertical Section of a Typical Field Geophone and Offset Layout 28

9. Refractive Wave Plot 31

10. Common Depth Point Stack of Regular Offset Data 32

11. Common Depth Point Stack Data Around the Area of Surface Ground Zero 33

12. Common Depth Point Stack of Wideangle Data 35

13. Common Depth Point Stack of Wideangle Data Around the Area of Surface Ground Zero 


\subsection{INTRODUCTION}

\subsection{Goals}

Nuclear testing being performed at the Nevada Test Site (NTS) occurs in two different geologic environments; hardrock (for effects testing) or alluvial / soft sediment (for de-coupling experiments). The series of seismic reflection surveys completed in July of 1992 (Piledriver, Hardhat, Tiny Tot, and Dining Car) were designed for the hard rock locations. The hard rock sites differ from alluvial sites in that they often do not show surface affects from explosions other than small landslides and cracked plaster on structures. These affects often are more aptly attributed to local geologic conditions such as preexisting structural and stratigraphic discontinuities (Borg, 1973) than to nuclear testing. Instead, the only manifestation which can be directly attributed to the detonation (besides the initial shock) is a characteristic subterranean cave-in, referred to as a chimney.

Piledriver was a $61 \pm 10$ kiloton nuclear event detonated June 2nd, 1966. The shot was funded by the Department of Defense (DOD) and consisted of a Los Alamos built device buried in a spherical cavity carved out of granite pluton at a depth of $463.1 \mathrm{~m}$. During the period of July $21 \mathrm{st}$ to August 2nd of 1967 a drilling program was funded to explore the chimney characteristics from the explosion (Boardman, 1967).

The results of this survey revealed the chimney height to be $277.3 \mathrm{~m}$ above the shot point, or, $185.9 \mathrm{~m}$ below the surface as shown in Figure 1. The original pre-explosion cavity diameter of $44.5 \pm 1 \mathrm{~m}$ was assumed to be nearly the same after the explosion although the formation of the chimney above meant that the cavity was no longer a true void. The report also noted that only a small (short) apical void was found. The apical void is the upper boundary of the chimney; a hollow area basically a nearly flattened half-spheroid. 


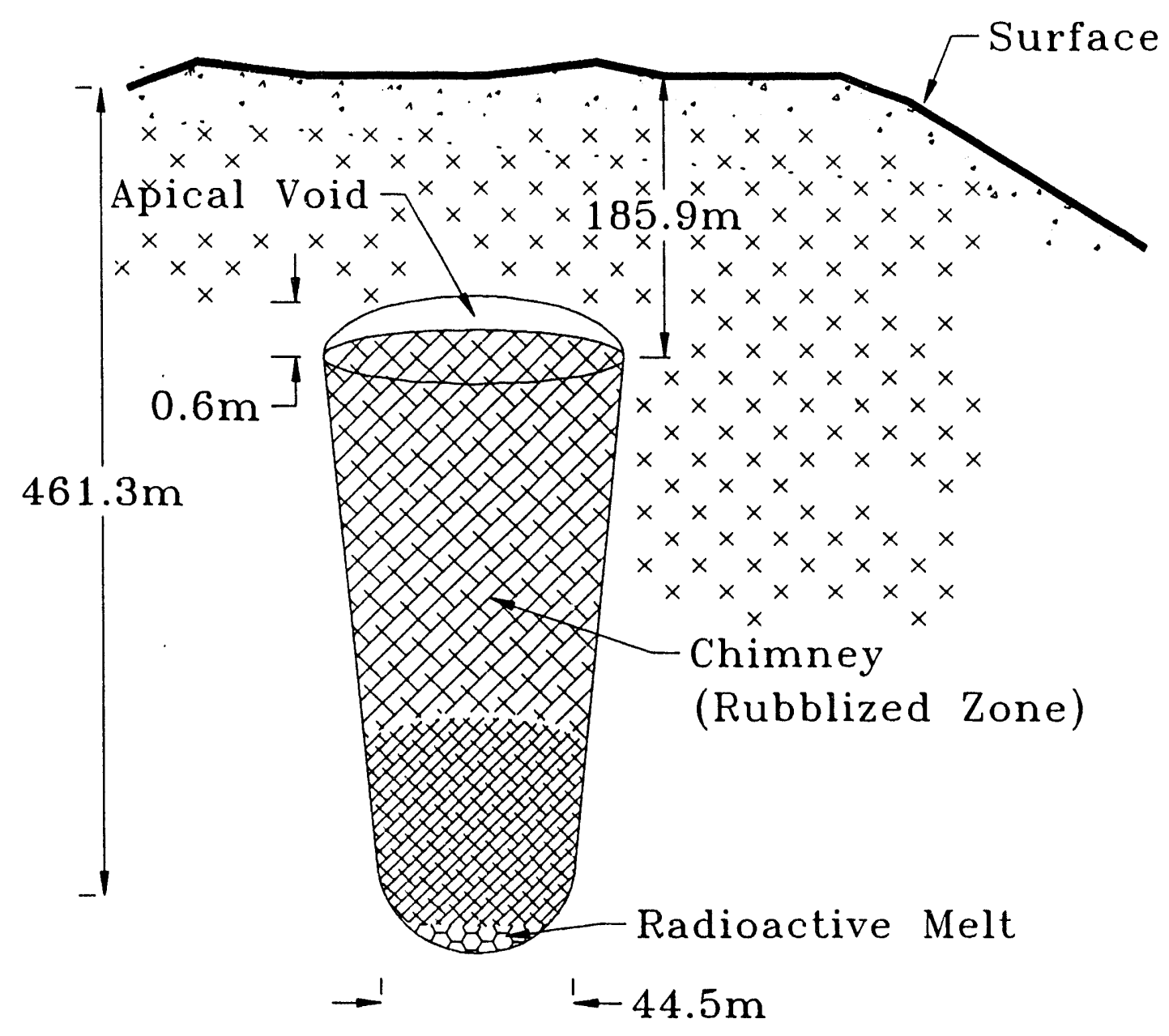

Figure 1 - Piledriver Event Diagram 
The scope of this study is to evaluate seismic reflection used at the Piledriver location both as a geophysical technique and as a seismic package. This analysis is done both in terms of quality of results and ease of data accumulation and reduction. This experiment is designed to accurately identify and characterize the chimney structure caused by underground nuclear testing in competent rock. The results could then be applied to foreign (governmental) sites which are under treaty not to test (or restrict testing to a certain yield weapon) and verify whether or not that nation has broken its vow. As a rule, this method would only be used when there is other pre-existing evidence to suggest testing in a region.

\subsection{Choosing the Appropriate Method}

There are many geophysical techniques which are capable of characterizing underground structures. Some require a small crew and little time to gather and process data while others are quite labor intensive and, therefore, very expensive to conduct. Many of these techniques are also limited in application due to requirements for certain physical characteristics. To select the appropriate method for this characterization study, all methods available were considered and one selected which optimized the results and economics.

\subsubsection{Electro-Magnetics}

Electro-magnetic (EM) methods measure changes in the earth's conductivity by producing an input signal which is transmitted through the earth and received and analyzed at a second point. EM methods comprise a wide range of systems including self potential (SP), induced potential (IP) and resistivity. Combinations of these have been employed to find subsurface voids or rubble-filled cavities (Didwall and Dease, 1984) as well as more conventional uses such as characterization of ore bodies and finding buried metallic objects (Gerety et al., 1989). Studies for voids were designed for depths of $\mathbf{3 0}$ meters or more with diameters on the order of tens of meters. Although results of the EM studies by Didwall and Dease (1984) for the particular test in question were better than 
expected, there are some problems with using that particular design under the application required for the Nevada Test Site (NTS).

The method is not intended to find a small cavity at a comparatively great depth. The use of EM may or may not identify the chimney shape and characteristics above the cavity. Although there may be some form of apparent fluctuation in readings due to the increased void spaces where collapse occurred, pervasive fracturing in an area well above the water table probably would not be visible on the record. In addition, extensive computer modelling is necessary in order to provide coherent interpretations; no interpretations can be made in the field.

\subsubsection{Magnetics}

Magnetic surveys are a popular geophysical exploration and characterization tool due to the fact that they require few people to take data, instruments (magnetometers and gradiometers) are relatively cheap and very portable, and data takes a relatively short time to process. When considering the detail constraints of the NTS survey, however, the method falls short.

Magnetics, like all electro-magnetic methods, require some form of conductivity anomaly in order to show a change on the survey record. However, results are often ambiguous as to depth, shape and size of the target. If a target is capable of generating an electrical field (such as a field associated with sulfide ore body oxidation) or is near a power line, results can become even less defined. While there are many drawbacks, magnetic methods still constitute a very useful tool for mineral deposit characterization and for a large variety of environmental surveys, for example, clearing large areas containing metallic objects such as buried drums and tanks.

\subsubsection{Gravity and Microgravity}

Gravity has, in the past, been considered the most time consuming of all of the geophysical 
techniques in terms of processing because of the detail of the data obtained in measuring the earth's gravitational field. Recent developments in computer programs have allowed more precise results and less time in the office. These improvements have caused a renewed interest in gravity methods, especially for small survey areas, mostly by mining and environmental firms. Recent interest has been in two directions: above and below ground measurements.

Underground measurements, such as those made in shafts, drifts and cavities, are undertaken with a number of purposes in mind. Depending on the type of company conducting the survey, these purposes could include density determination, exploration or safety controls. Casten and Gram (1989) report that underground measurements were used to accurately locate an underground pump room. In fact, further data manipulation that provided the horizontal gradient (change in measured gravitational acceleration over distance) proved even more useful than the original individual point source data by providing a more detailed view of the target. Although this additonal information was gained, 3D computer modelling to account for cavity effects was necessary during data reduction. The required additional modelling, combined with radiation safety concerns in the drifts around the sites involved in this project, eliminated underground gravity surveys.

Above ground measurements eliminate the threat of hazardous levels of radiation and have been used to locate large underground cavities and tunnels. One method, developed primarily for geotechnical purposes, can be used to detect shafts with diameters up to 3 meters to depths of over 10 meters (Dresen and Elsen, 1982). Another method, using microgravimetric equipment, identified both an air filled cavity system about 10 meters deep and a water filled cavity system about 30 meters deep (Butler, 1984). Unfortunately, both of the surface methods are incapable of finding a cavity as located at the test site. 
1.2.4 Radar

Ground Penetrating Radar (GPR) is known as a method of high precision, however, it is also known as a method of low penetration. GPR is based on the same theories and modes of operation that (air) radar or (sea) sonar are. Signals are transmitted into the ground and are bounced back by reflective media, in this case, different lithologic layers. Typically, radar can be used efficiently to find shallow (less than about ten feet deep) cavities, pipes and cables. More recent (and less conventional) applications include characterizations of archeological sites (Tsuneo et al., 1987) and petroleum contamination plumes (Olhoeft, 1986). Surveys for previous excavations in tuff conducted at Los Alamos National Lab (LANL) have yielded no useful results (Gerety et al., 1989). In fact, no sign of a waste pit, known to be at the location of the survey was visible, although the depth to the top of the pit is less than 2 feet.

This lack of penetration is apparently a limitation of the current equipment and will hopefully change as advances in power or signal conditioning are made. Until these advances take place, this method is inappropriate for the detection of cavities at depths that occur at NTS.

\subsubsection{Seismic}

Because cracks, fractures and joints significantly affect the mechanical behavior of rocks and rock masses (Wu et al., 1991), seismic velocity is affected. By measuring this velocity with a method like seismic refraction or reflection, determinations can be made about depths and shapes of certain targets.

The relationship between seismic analysis and nuclear events is fundamental and can be traced back to the first test on the 16th of July, 1945. This first analysis was simply to estimate the strength of the blast based on the record of a three-component seismograph (Leet, 1946). The three-component seismic method has continued to the present having peaceful international 
applications (such as nuclear verification) with very little change in function or purpose (Ringdal et al., 1991). Still, this particular application of seismics cannot yield the information being sought in this survey.

Seismic refraction makes use of waves which are "bent" when a wave pulse intersects a layer of different velocity than the one currently being travelled through. In practice, however, refiaction has problems because of its inability to combine surveys into a profile of a target area as well as having some layers "hidden" due to slower velocity layers being encountered. This second problem can result in inaccurate velocity measurements and unmapped layers leading to false depth readings and inaccurate stratigraphy interpretations.

Recently, seismic reflection mapping has proven to be an effective tool when overburden exceeds $20 \mathrm{~m}$ in thickness (Hunter et al., 1984). As opposed to geophysical techniques previously outlined, seismic reflection has the advantage of allowing qualitative interpretations of geologic features such as the throw of faults, defining fold structures and tracing intrabasement horizons (Nelson, 1982).

High resolution seismic reflection is the newest extension of the overall method. It is characterized by a broader frequency being recorded, mainly facilitated through extension of the high frequency end of the spectrum (Ziolkowski and Lerwill, 1979) as supplied by the source. High resolution seismic reflection has been shown to be capable of detecting minor faults of about five meters throw at a depth of $800 \mathrm{~m}$.

To explore the capabilities of the high resolution seismic method, and to evaluate its usefulness, the test conducted by Miller and Steeples (1992) was studied. Using a 50-caliber gun as a seismic source (and otherwise using similar equipment to that available for the Piledriver tests), 
the results of this project were able to delineate fairly accurately spall associated with underground nuclear blasts in alluvial areas. Spalling structures are somewhat difficult to discern under these conditions because they occur typically as discontinuities between identical alluvial layers. This means that the seismic velocity on either side of the discontinuity is nearly the same and may thereby disguise the spall plane as simply another sedimentary bed. Yet Miller and Steeples (1992) proved the flexibility of the method by identifying some spall layers in the alluvium through reflection of signals off the thin spall planes between the beds.

Seismic reflection has gained wide acceptance as a method to characterize a number of different situations. Reflection work in mining has taken a particularly intense jump, both in characterization associated with new mines and reclamation of old (Dresen et al., 1982). This method is used frequently in coal mining on account of its ability to accurately map the extent of production size deposits (Greaves, 1985) and faults which can cause serious stability problems (Gochioco and Cotten, 1989). Also, work has been successfully performed using the method to remotely evaluate subsurface alluvial stratigraphy around a proposed industrial waste disposal site (Knapp et al., 1983). Because of its proven reliability, breadth of application and ease of equipment aquisition and use, high resolution seismic profiling was selected as the method to evaluate the chimney structure at the Piledriver site.

\subsection{Components of Seismic Surveys}

The results of seismic surveys rely on many individual components, all of which are dependent on the aim of the survey and the media being explored. The following section identifies and explains:

1) the major components of the seismic reflection system used at NTS and

2) the system used during processing 


\subsubsection{Source}

Sources vary greatly in both frequency cuntent and energy. Some of the best results for seismic reflection surveys will result from sources which are composed primarily of high frequencies. This reason for this is that low frequency energy is not capable of generating greatly detailed reflections. However, the problems of multiples or "ghost" reflectors (Rüter and Schepers, 1985) and low-pass filtering by the rock (Almossawi, 1988) become more severe with high frequency sources.

Sources can be separated int. three categories on the basis of their energy production. Projectile, explosive and m, unanical energies are commonly used. Of these, explosives provide the widest range of energy while mechanical sources provide the best control of frequency. Before discussing each group individually, it should be noted that some types of sources defy classification in these groups as they may have attributes of more than one group. Examples of these are airguns, propane oxygen detonators (POD) and spark packs ("sparkers"). Some of these sources are specialized to certain applications (such as the airgun), hut none are appropriate for the circumstances at the test site, and hence will not be discussed.

\section{i. Projectiles}

Projectile sources are very common. They are powerful, economical, repeatable and relatively easily available. They are all basically different caliber rifles aimed at the ground, some with modification (such as the "Betsy", 8-Gauge gun) to improve the quality of the signal imparted to the ground and the ease of setup and mobility. Much work has been done comparing various guns such as 30.06 rifles and 8 and 12 gauge shotguns (Miller et al., 1989). Figure 2 shows the relative signal amplitudes produced by the three guns mentioned above. Surprisingly, blanks, rather than slugs or shot, produce the greatest energy, although no plausible reason has been advanced for this behavior.

Frequency response from projectile sources varies greatly. Muzzle velocities of most 


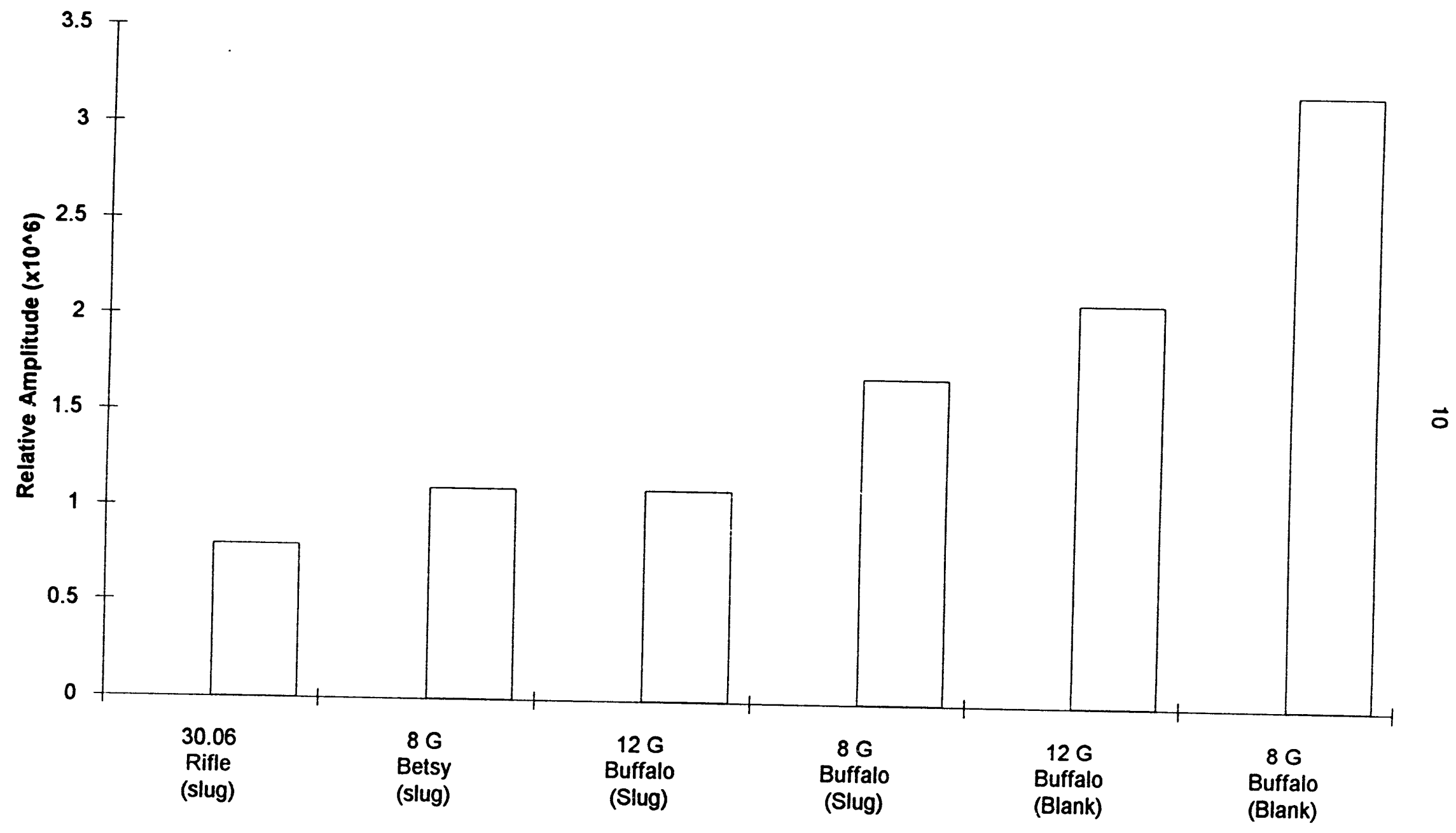

Figure 2 - Relative Amplitudes of Various Projectile Sources 
common "seisguns" range between 2000 and 4000 fps (Steeples, 1984). Upon impact with the surface, a hypersonic shock wave is created with the majority of the energy focused downward. Even as the bullet's speed slows the compressional energy will be Doppler shifted to boost the high frequency end of the spectrum. The high frequency boost is actually an "anti-Doppler" effect where, instead of the bullet moving away from the surface of the ground (and shifting the source energy lower), the bullet's action is more like two objects (in this case, itself and the receiver) approaching each other. More wave fronts (of seismic energy) will arrive at the receiver at the same time creating the affect of a high frequency signal.

All sources require a good energy transfer, or coupling, to the media and projectile sources are no exception. Most often, coupling is associated with the incoming signal (the receiver), and so coupling will be explained at that point. A common method to provide good coupling for sources is to fire the gun into a water filled hole. All shots illustrated in Figure 2 are fired into a water filled hole. Without the aid of water coupling, a steep high frequency roll-off occurs which can obscure layers in some media. In other words, frequencies of around $50 \mathrm{Hertz}$ and higher are attenuated rapidly over distance, leaving only the less defining, lower frequency waves to indicate the presence of the layers. Even with water coupling, however, sufficient energy is not present to conduct a survey to the depths required without multiple sources (numerous guns, in this case, fired simultaneously) and high stacks of data (summed layers of seismic records).

\section{ii. Explosives}

Explosives have been used extensively as sources from the very beginning of seismic surveying. When considering how much force is imparted, the amplitude of earth movement is proportional to the square root of energy released by the explosive. Unfortunately, ideal circumstances seldom exist. Extensive research by Habberjam and Whetton (1952) using routine quarry blasting revealed a complex relationship introducing variables such as a site factor and 
weight of explosive. Later studies have further attempted to define the relationship by replacing weight with actual explosive characteristics and modifying the site factor to include coupling methods.

The quest for better control of frequency response has led to explosives being designed and/or applied only for specific applications. Traditional explosives such as dynamite are deeply buried (in some cases, in boreholes) to provide sufficiently broad-band seismic signals (Greaves, 1985). The technique of placing these more common explosives below the water table, or, at least below the weathered layer greatly increases frequency response. Further increase has been achieved by using shaped charges such as shown by Steeples (1984). His work shows that shaping surface charges can cause the energy wave to propagate downward like that of a projectile, instead of radiating outward (geometric dispersion) as it would otherwise. This dispersion can lead to an almost seven time decrease in useful, downward compressional energy.

However, it is almost impossible to obtain a permit for the use of even small explosive charges for exploratory purposes at NTS. Unless a large amount of time is spent in preparing applications, standard operating procedures and hazard courses, only the final group of sources, mechanical, could realistically be considered for this survey.

\section{iii Mechanical}

Mechanical sources are all physical impulse in nature, however, they vary largely in technique and energy output. The least powerful of the common mechanical methods is a hammer striking a plate coupled to the ground or a gravity drop. The gravity drop (typically a bag filled with lead shot dropped from a predetermined height) provides the benefit of being extremely repeatable while the hammer and plate is very portable and usually provides ample high frequency energy for most shallow seismic reflection surveys. 
The next step up in energy output is the Elastic Wave Generator (EWG), illustrated in Figure 3. It is a fairly simple tool consisting of a slingshot aimed at the ground. Energy output and frequency response surpass even the most efficient projectile sources as shown in Figure 4. These factors allowed it to be used effectively as the source of energy fo; ? refraction study to sample velocities in various geologic medias. Still, it did not provide adequate energy to allow it to be used as the source for the main reflection studies.

The most powerful mechanical sources are the Vibroseis ${ }^{\circledR}$ (vibe) and Mini-Sosie (Hageman, 1982). Mini-Sosie is, in itself, a complete topic for a report; not so much a source as much as it is an entire seismic method. Mini-Sosie often employs either a single vibe or, more usually, an array (Mair and Green, 1981). The Vibroseis ${ }^{\bullet}$ (designed by CONOCO) isi engineered to be completely flexible in terms of energy and frequency response within the limits of common seismic surveys. A typical vibe truck consisis of a large plate which transmits energy to the media as generated by an intricate hydraulic system. The hydraulic system, in turn, is usually governed by a computer which can vary the intensity and frequency of the signal over time. Often referred to as a chirp or sweep, this means of imparting seismic energy is very effective in transmission of high frequency energy to most media. However, because a sweep occurs over a considerable period of time, it requires a longer seismic record and later correlation of the data to the actual signal imparted to the ground. Still, the Vibroseis ${ }^{\oplus}$ produces the most effective signal in terms of strength and frequency for the cavity survey and was therefore selected as the source for this seismic reflection experiment.

\subsubsection{Geophones}

The first step in the signal path to the recorder is the geophone. Analogous to the microphone in design and function, the geophone, shown in Figure 5, serves to convert mechanical motion of the ground into electrical impulses whose amplitude is proportional to the velocity of 


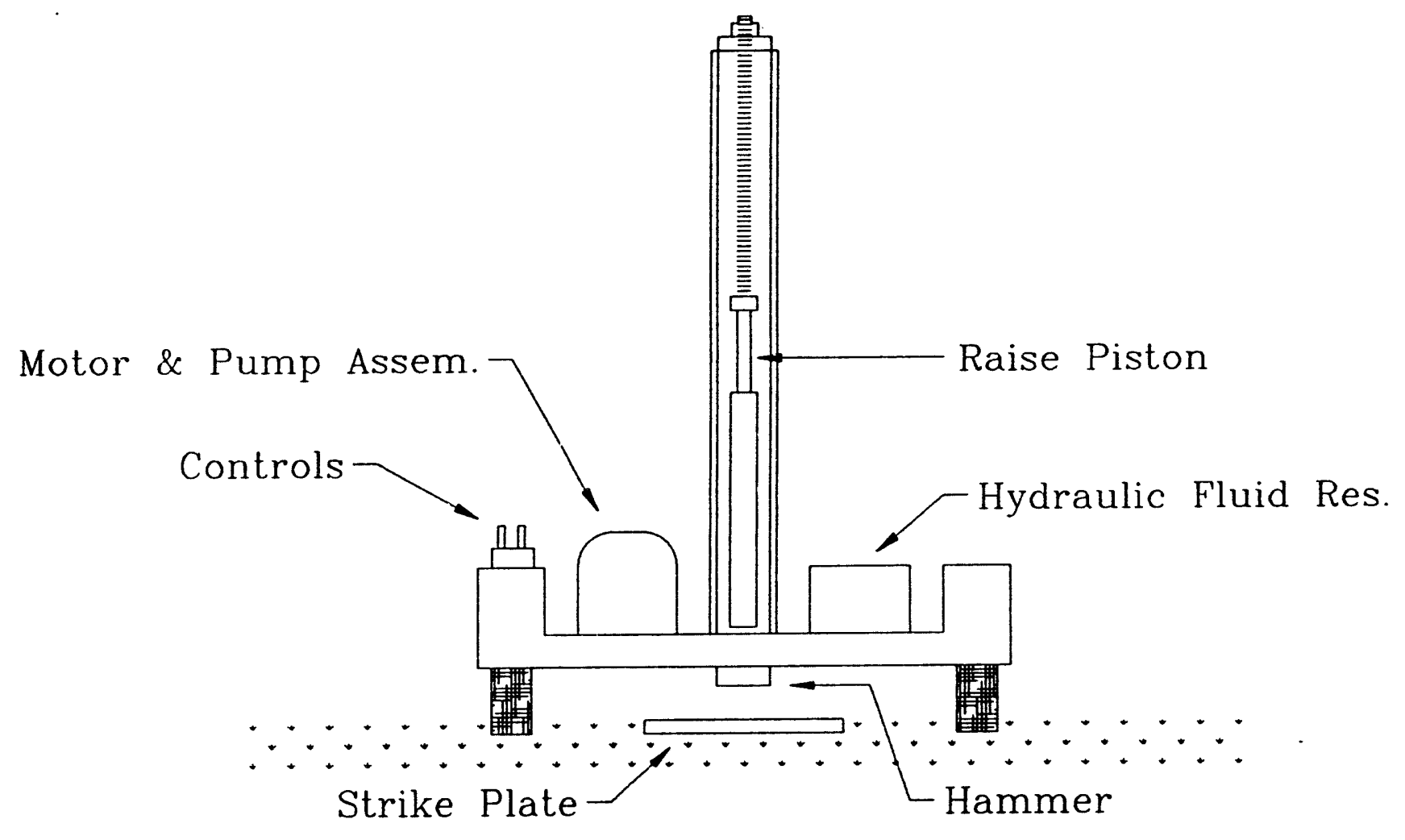

Figure 3 - Elastic Wave Generator Diagram 


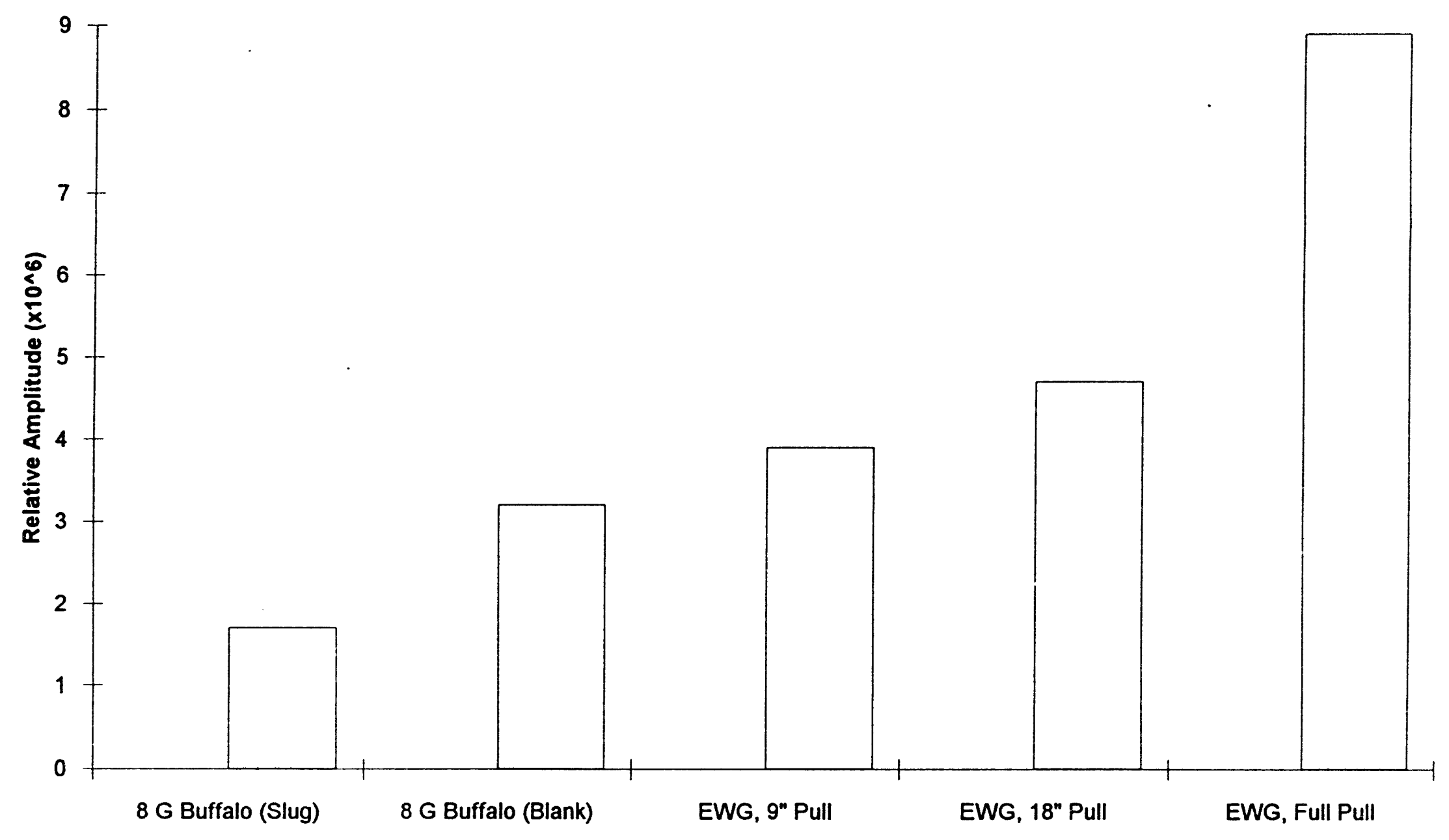

Figure 4 - Relative Amplitudes of an Elastic Wave Generator vs. Projectile Sources 


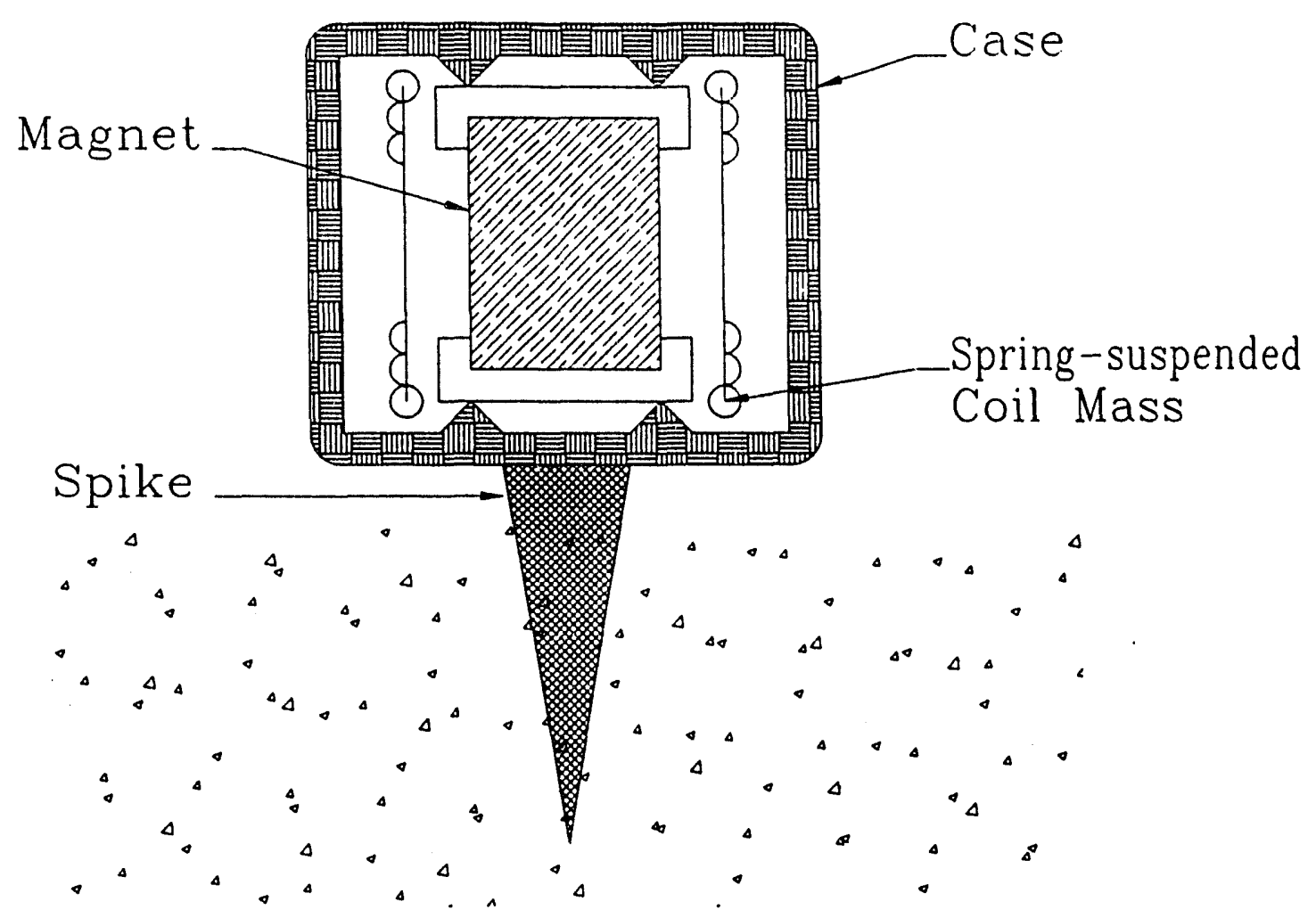

Figure 5 - Geophone Diagram 
motion. The actual components of a geophone are relatively simple. Knapp and Steeples (1986), amongst others, give detailed descriptions of geophone components.

In order to accurately characterize the attributes of the impulse, the phone must be suited to the source in terms of frequency response and the medla in terms of coupling. The nature of the survey at the test site called for a predominance of high frequency energy which, therefore, called for a phone with a relatively high resonant or natural frequency. To meet this, Mark Products $40 \mathrm{Hertz}(\mathrm{Hz})$ phones were chosen. Under certain conditions geophones with higher resonant frequency may be required, as the dominant frequency of some reflectors have been shown to be as high as 300 to $400 \mathrm{~Hz}$ (Knapp et al., 1983). Data relating to the reflective characteristics of the geologic region within NTS, however, remains largely unavailable.

Once the geophone itself has been selected, the next step is to choose an array pattern and coupling method which will provide sufficient energy transfer to produce a clear record. A functional array pattern is a layout of phones, which, when placed in sequence or parallel can increase gain and at the same time reduce destructive body (Rayleigh) wave interference, such as ground roll, in the record. The standard method of planting a geophone is simply by using either a 3 or 5 inch spike attached to the base of the geophone and inserted in the ground. The longer spikes provide a slightly better signal, but, they require at least 5 inches of unconsolidated material on the surface. Unfortunately this depth to hardrock was not available at any of the locations, leading to the use of 3 inch spikes for the surveys. The lack of unconsolidated material became an obvious problem at Dining Car (a site where a similar survey was conducted) where some areas of rock were exposed. In such areas, special considerations had to be made as to the method of coupling.

Independent testing prior to the NTS survey confirmed and quantified the results of Krohn (1984). This independent testing proved that coupling can be greatly improved, increasing signal-to- 
noise ratio (usable signal vs. background noise) up to $500 \%$ as shown in Figure 6 , by simply covering the phones. Therefore, in areas where poor coupling was suspected, phones were covered to provide a sufficiently coherent signal. In the special case of trying to "plant" phones on bare rock, common RTV (automotive gasket sealant) was used to secure the base directly to the surface, and then the phone was covered with surrounding soils. Typically, the RTV should be allowed to set at least 4 hours prior to trying to record but time constraints forced use as short as 1 hour after being ernplaced. A further discussion on coupling affects is found in Appendix 1.

\subsubsection{Recording}

For the NTS survey, an EG\&G ES2420 digital reflection seismograph was employed for recording data. This unit is similar in design to that shown in Figure 7 and incorporates both automatic gain control and 32-bit analog/digital conversion, resulting in a useable signal-to-noise ratio of about $100 \mathrm{db}$. This range is nearly twice that of a standard 12 channel engineering seismograph such as the EG\&G ES1224. The ES2420 also provides a number of additional features, such as bandpass filtering, which are otherwise needed when processing data (Mair and Green, 1981). Further specifications are given in Appendix 2.

From the recorder, the wave forms were transferred to an EG\&G DMT2420 portable digital magnetic tape drive. The drive uses an 8.5 inch reel (maximum) and has a tape speed of 37.5 inches per second. Although it served its purpose adequately, certain deficiencies such as excessive power consumption and small data handling capability per tape became apparent during the surveys. For example, if available tape supplies are limited, adjustments to the sampling rate (the number of times per second the incoming signal is recorded) would have to be made in order to conserve space resulting in a loss of data quality. 


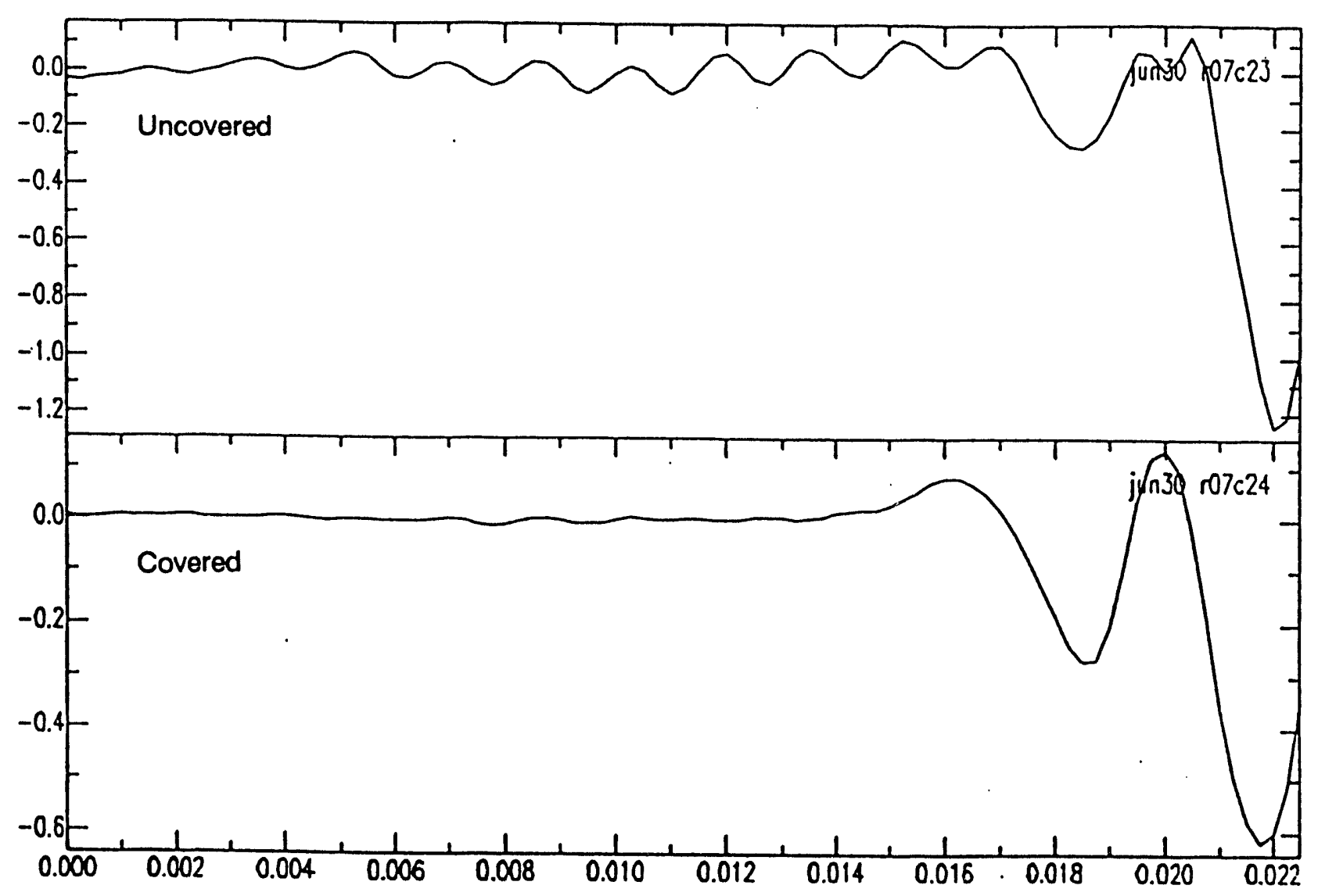

Figure 6 - Demonstrated Increase in Signal-to-Noise Ratio via Covering 
Channel 1

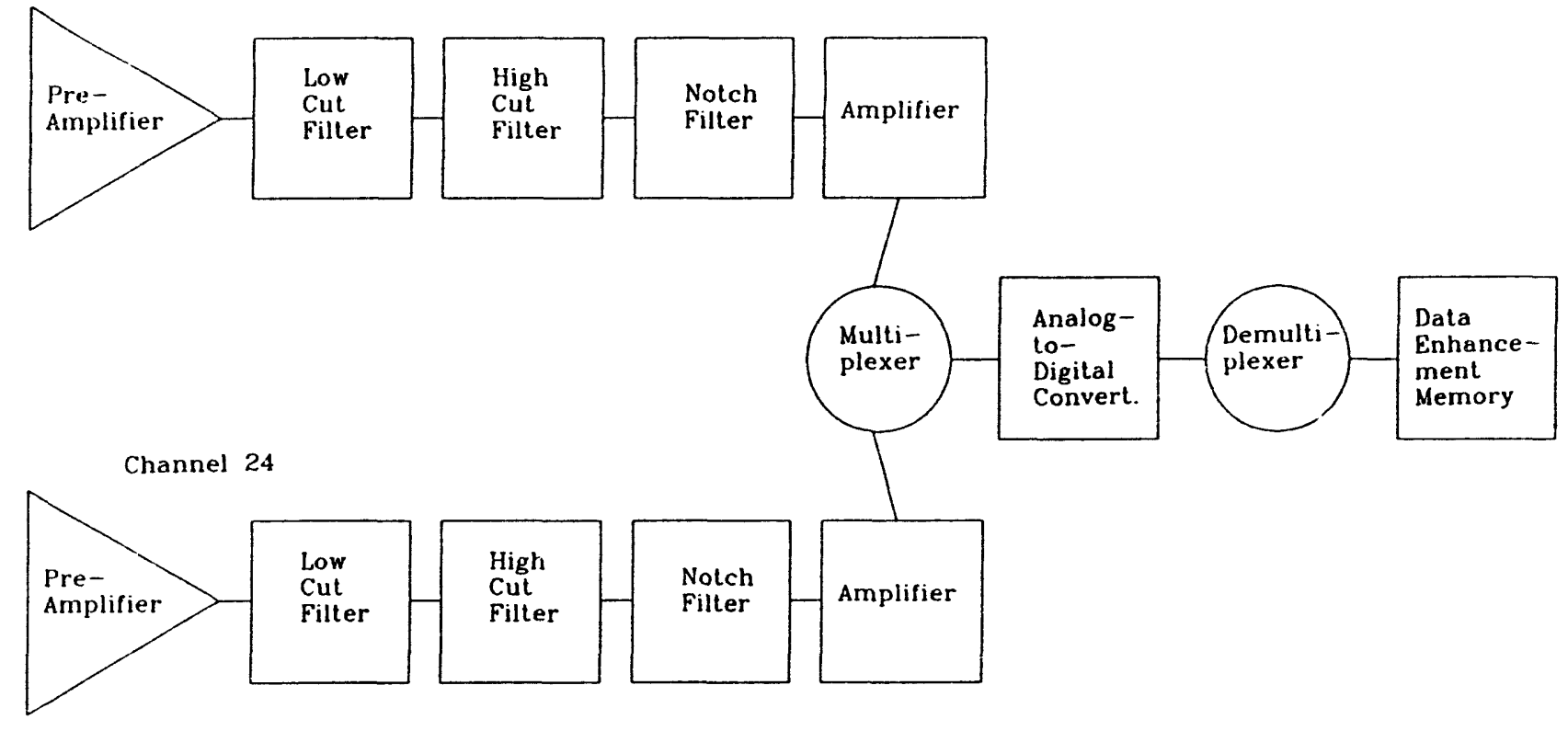

Figure 7 - Flow Path for Signal in a Digital Reflection Seismograph 


\subsubsection{Processing}

The majority of the data processing involves the use of the DOS based Eavesdropper series which was developed by the Kansas State Geological Survey and is marketed by Interactive Concepts. Eavesdropper runs most efficiently by using a macros file referred to as a deck to call up individual subroutines (in this case, individual steps in overall seismic analysis). A complete deck will include all of the components illustrated in Table 1, although some steps can be eliminated based on the quality of the incoming data and the result desired.

Of the processes shown in Table 1, two of the most important are manipulations based on velocity information. Normal moveout (NMOT) is an adjustment of the wave arrivals within a shot gather (a particular collection of channels recorded simultaneously) to account for surface anomaly layers. Stacking velocity adjustments (evaluated by using VSCN) are designed to shift the data with respect to time. Both of these time oriented adjustments are designed to prevent improper decisions as to depth of a reflector when viewing the stacked data.

Some editing features not included in Table 1 are designed to cleanse the signal of system or recording noise prior to actual processing. These features allow muting, or elimination, of first (refractive and air wave) arrivals and surgical muting to remove unwanted noise, later refracted arrivals, or other wave anomalies from within the record. If the muting features were not available, there may be apparent reflective bodies in the final record which do not actually exist in the media. Muting may cause some removal of information from a shot gather which will cloud the true reflective record. In general, muting must be done with great care to only remove the portions of the record which are clearly refractive.

The second program (SIPIK๑) is produced by Rimrock Geophysical Software and was used only to pick the first (refractive) arrivals. Raw ES2420 files can be converted to a readable data 
Table 1 - Complete Eavesdropper ${ }^{\oplus}$ Processing Deck

$>$ > start

*INPF generic.kgs

*AUED 100.25011

*EDKL 928

kill 11024

*EDFM 928

tapr 10

farm 117520

^EDMT 928

tapr 10

mute 1320034150400

*SORT 12191

ptrn 5240

pn 1101111241

SHOT

snsn $<1621><1011621>1$

tabl 00

*SURF 5000

alvf 5009.7032004900

se 014998.625001 .11

*NMOT 0.5

velf 17017500

*STAK 1

*OUTF stacked.kgs

$>$ > end
Announces start of deck to Eavesdropper

Define input file, in this case, GENERIC.KGS

Note, the file must be in KGS (modified SEG-Y)

format

Begins auto-edit feature; 10 is minimum

allowable signal-to-noise ratio before muting the channel, 0.25 is the length of the record to check

Begins edit-kill feature

Kills channels 2 through 4 of records 1 through 10

Begins edit-first-arrival feature

Defines amount of record to taper from end of specified mute

Mutes (in record 1) channel 1 intil $75 \mathrm{msec}$ and channel 2 to $0 \mathrm{msec}$ (not at all)

Begins surgical-mute of selected channels

Same as previous tapr command

Mutes (in record 13) channel 2 not at all,

channel 3 from 41 to $50 \mathrm{msec}$ and channel 4

not at all

Begins sort feature

Defines geometry of the set-up; 5 units between stations, 24 channels per record, length units are feet

Beginning setup is source at 101 , first phone at 111,24 channels in all

Initialize shot command

Define sequence; first record $=1$, last

record $=62$, corresponding first station of

source $=101$, last $=162$, records increment by 1

station

Eliminates table in output file

Starts surface command and sets Datum $=5000$

Sets maximum elevation (5009.70), velocity of

first layer (3200) and elevation of first interface

(4900)

Sets source and 1st receiver height for record 1

Starts normal moveout command and defines

maximum stretch

Sets velocity of layer 1 as 17500 for the first 70

msec

Starts stacking procedure

Defines output filename (STACKED.KGS)

Announces end of deck to Eavesdropper 
format, picked, and the results transferred to a common graphing program (such as Grapherब) to plot the velocity curves. The velocities found can be then used as guides during NMOT and VSCN calculations in Eavesdropper. No formal deck is needed to control operations for SIPIK as it is fully interactive and menu driven. 


\subsection{FIELD DATA ACQUISITION}

\subsection{Introduction to the Field Methods}

Once seismic reflection has been chosen as the geophysical method, and the equipment for the survey has also been selected, the emphasis of the survey turns to the field. Due to the fact that the survey is to be conducted at NTS, several constraints for field surveys carry strong influence on the field set-up and data collection. As indicated already, explosives were basically eliminated as a possible source due to extreme measures which would have to be adhered to when using explosives at NTS.

Similarly, another constraint is the accessibility of an area. For example, although the seismic line should be run directly over the center of the chimney structure, possible limitations due to historical or natural preserves dictate the area which can be entered and a direction to progress. No question can be pursued at this point as to whether or not the survey's usefulness will be compromised so long as the restricted area is not disturbed.

\subsection{Hazards}

During any geophysical study, awareness of hazards must be recognized. Although hazards were not encountered during this survey, numerous hazards could have presented themselves as possible obstacles to be overcome.

For example, one year after the initiation of Piledriver, an exploration shaft was sunk to evaluate the chimney created by the blast. Although this shaft (and the original bomb emplacement drifts) were backfilled. they were vented slowly over time, releasing small amounts of radiation 
(Anonymous, 1986). Fortunately, this site is of sufficient age, and the chamber is of sufficient depth that the likelihood of serious radiation exposure is extremely limited.

Natural hazards in the area were mostly limited to poisonous snakes, however, this risk was extremely small as the amount of activity in the area discouraged most animals from remaining in the vicinity. Certain fauna native to the region such as cactii, mesquite and yucca trees also presented some dancer.

Another prominent hazard in this study is that associated with working around the two seismic sources. The EWG presents the possibility of projectiles as components of the device may shear while the unit is applying force. The Vibe, on the other hand, could present a more serious danger to the environment, rather than to personnel in the area. A high pressure hydraulic line break would release a large quantity of hydraulic fluid into the soil. If acted upon promptly, only a small area might be affected, but if left to soak in for an extended period of time, the effects may be quite severe.

\subsection{Limitations}

The limitations imposed on this survey can be grouped into those that are presented by topography, weather, and historical or natural preserves. Of these three, the least likely to be overcome is the presence of restricted areas due to natural or historical preserves. Regulations governing access to these areas are very strict and quite explicit, making any trespass nearly impossible. Although there are numerous restricted areas around the study sites, none of them presented an immediate problem.

The easiest limitation to overcome is adverse weather conditions. One possible weather problem is that presented by nearby electrical storms, which can add noise to the seismic record 
and pose a danger to personnel operating in the area. Further, the high air temperatures in the desert and the need for cool operating temperatures for computer equipment can present an operating problems. The problem of over-heating was rarely encountered and never caused a major problem. As a contingency, however, the recording trailer was equipped with air conditioning which could be powered by a nearby gasoline generator.

The final problem, topography, was the only one of significant consequence encountered in the field. At the very least, topography dictated the orientation of the survey by providing only one reasonably flat orientation on which the vibe could operate. More directly, the limited amount of level ground at the location forced the use of a shorter than desired near offset or distance between the seismic source and the first phone. Ideally, the area should be flat, or, at the very least, be sloped gently enough to allow equipment to move freely across the area of the survey. If problems with topography at this location had been more severe, it would have been necessary to bring in earthmoving equipment in order to allow the vibe an adequate distance to traverse.

\subsection{Spacing}

In order to best record the reflected signal from the cavity and/or chimney interface, geophone spacing should be estimated so as to as precisely as possible define the surface of the buried structure. Similarly, offset (the distance between the source and a chosen receiver) should be estimated prior to starting the survey in order to reach the proper depth. Generally the closer the spacing of phones, the more detailed the overall record. In the case of this survey, the exchange of time versus detail dictated a station spacing of five feet. The calculations for the offset are based on properties of the media and the parameters of the survey including velocity of the media $\left(N_{1}\right)$, depth to target/layer $\left(h_{1}\right)$ and arrival time(s) of the wave. These factors can be seen as used in Equation (1). 


$$
\begin{aligned}
& t=\left(x^{2}+4 h_{1}{ }^{2}\right)^{k} / V_{1} \\
& \text { where } t=\text { intercept time } \\
& x=\text { offset } \\
& V_{1} \text { and } h_{1} \text { are as defined above }
\end{aligned}
$$

To determine an appropriate near offset given the other parameters, Equation (1) can be solved for $x$ as:

$$
x=\left(t^{2} V_{1}^{2}-4 h_{1}^{2}\right)^{n}
$$

Using $5000 \mathrm{~m} / \mathrm{s}$ as the estimated velocity in granite (Burger, 1992), an expected target depth of approximately $180 \mathrm{~m}$, and a desired wave arrival (intercept) time at the first phone of 100 ms (late enough to not be easily mistaken for surface waves, air waves or refracted arrivals), Equation (2) yields a near offset value of nearly $350 \mathrm{~m}(1138 \mathrm{ft})$. This value is inappropriate because the source would have to be very powerful and the region relatively flat and seismically quiet in order for the wave to travel the required distance undisturbed. As a second approximation, consider a slightly slower speed of propagation in the granite of $4000 \mathrm{~m} / \mathrm{s}$ and an arrival time of $90 \mathrm{~ms}$ typical of near surface weathered rock. Using these values in Equation (2) yields a near offset of about $15.24 \mathrm{~m}(50 \mathrm{ft})$. This second value is both reasonable and convenient because it allows a near offset of 10 geophone spacings as shown in Figure 8. It is also about the longest achievable due to the topography of the area.

It should be noted that geophone arrays (patterns of geophones at each station) were not considered in regards to the selected equipment. Although preliminary geophone testing at the site would have been the best method to examine an array's usefulness, it is generally regarded that even a short (small linear) array acts as a filter which attenuates higher frequencies (Ziolkowski and 


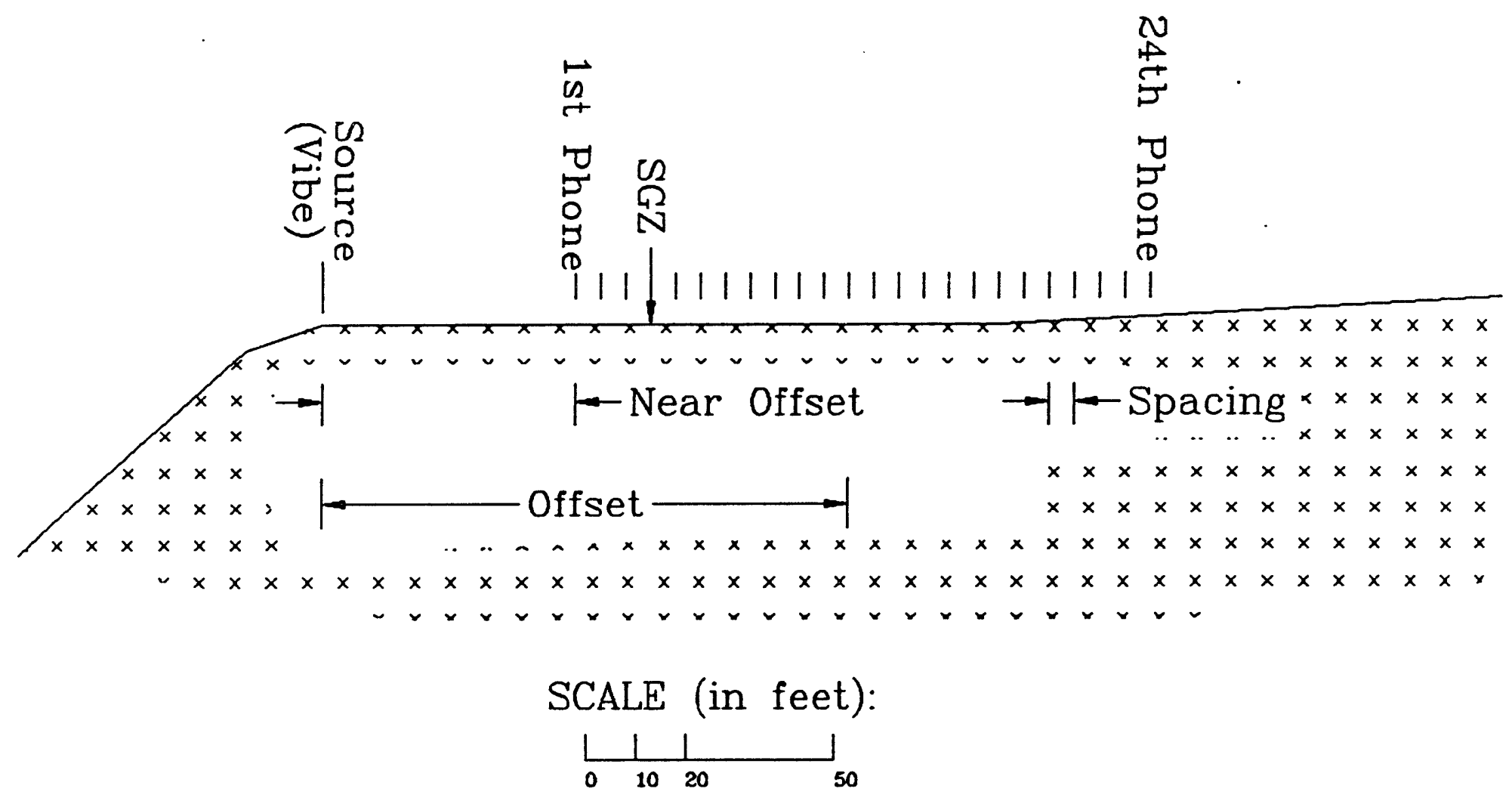

Figure 8 - Vertical Section of a Typical Geophone and Offset Layout 
Lerwill, 1979).

\subsection{Recording Parameters}

Because of expected problems with ground (Rayleigh) and air-coupled (sound) waves interfering with the record, some attempt has to be made to limit their interference in the field. Ordinarily, these affects can be greatly reduced by careful planning for geophone spacing, however, as mentioned already, limited availability of relatively flat topography takes precedence.

The next step is to adjust the recording frequencies to reduce those bands associated with the problem waves. This is usually accomplished through the use of elther a low cut or high pass filter. With this survey, the high pass filter was set at $100 \mathrm{~Hz}$ which roughly corresponds to the low end of the vibe sweep. Many refraction tests were also conducted with this setting although the refracted wave is usually of sufficient strength as to still be clearly visible through the ground and air waves. 


\subsection{DATA ANALYSIS}

\subsection{Processing}

The processing of the field data obtained in this survey involved initial field review, refractlve wave analysis and plotting, noise removal from individual records and Common Depth Point (CDP) stacking. The collectlon portion of this experiment went reasonably well, with only a minor connecting problem between the seismograph and the vibe. Immediate review of the records showed nothing extraordinary about the quality of the data.

Picking and then plotting the arrivals of the refractive waves revealed that the granite (beneath 30 meters) has a seismic velocity of about $5200 \mathrm{~m} / \mathrm{s}$ as shown in Figure 9 . This velocity value is close to the expected velocity for competent granite $(5000 \mathrm{~m} / \mathrm{s})$, but not close to that used for the calculations for offset $(4000 \mathrm{~m} / \mathrm{s})$. This discovery indicates that the reflected arrivals will be in the seismic record sooner than anticipated. Data manipulation to correct for overloaded channels (corrupted wave forms due to too strong of a signal, le: peaked), topography and normal moveout did not reveal any abnormally poor performance on the part of the entire selsmic system.

CDP stacking was next applied to the shot gathers. CDP stacking is designed to enhance the signal-to-noise ratio (similar to covering geophones) by stacking or adding common stations. In other words, channels which represent signals recorded at station 10 , for example, are all added together with respect to time. This results in wave forms caused by reflection being added while background noise and refracted waves are reduced due to their random nature (with respect to time). CDP stacking revealed very little in the way of reflective data as shown in Figure 10. A closer view of the area surrounding surface ground zero (SGZ), the point on the surface directly above the detonation site, reveals that no apparent structure is visible anywhere above $100 \mathrm{~ms}$. This can be seen in Figure 11. 


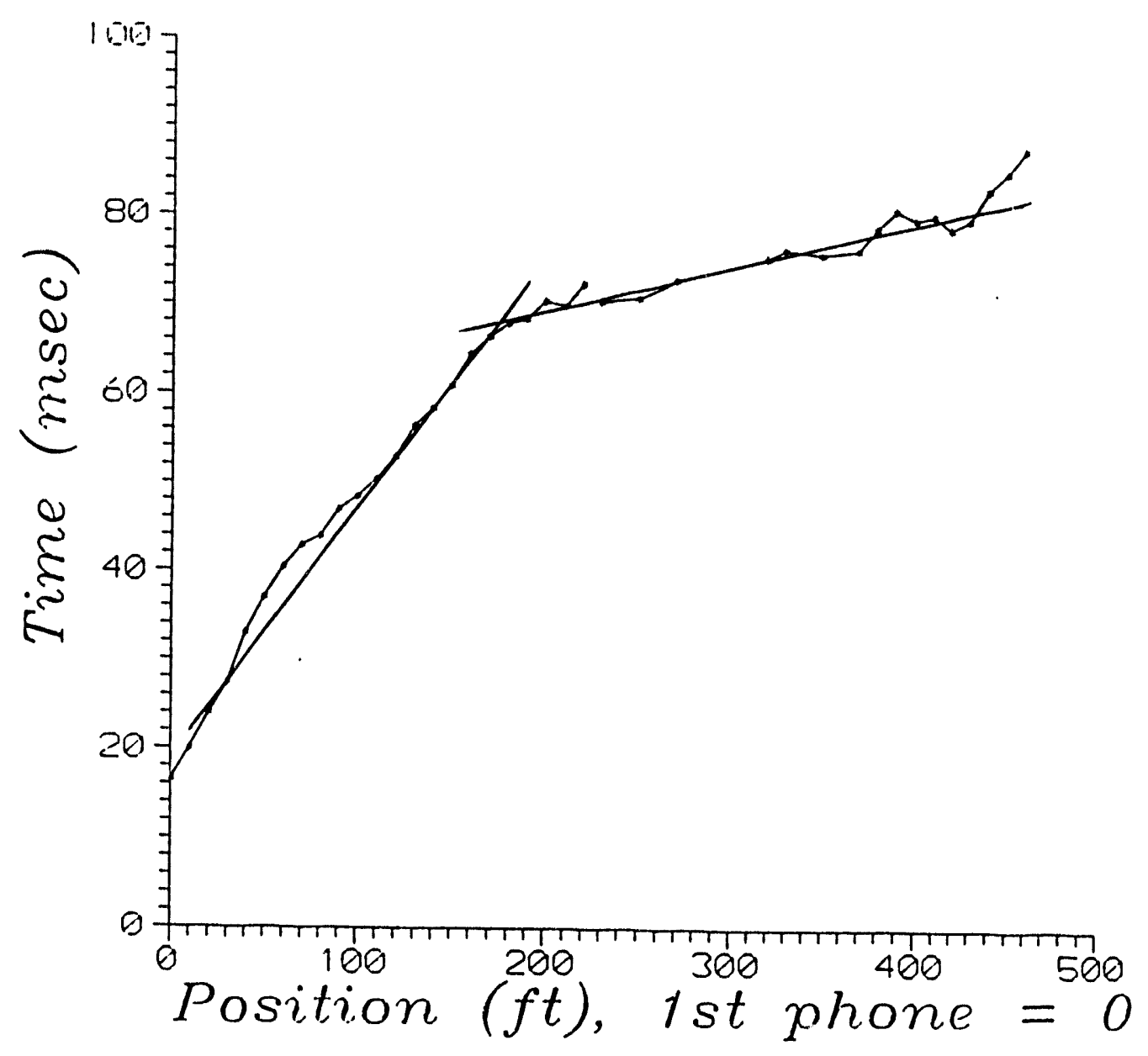

Figure 9 - Refractive Wave Plot 
Figure $10 \cdot$ Common Depth Point Stack of Regular Offset Data

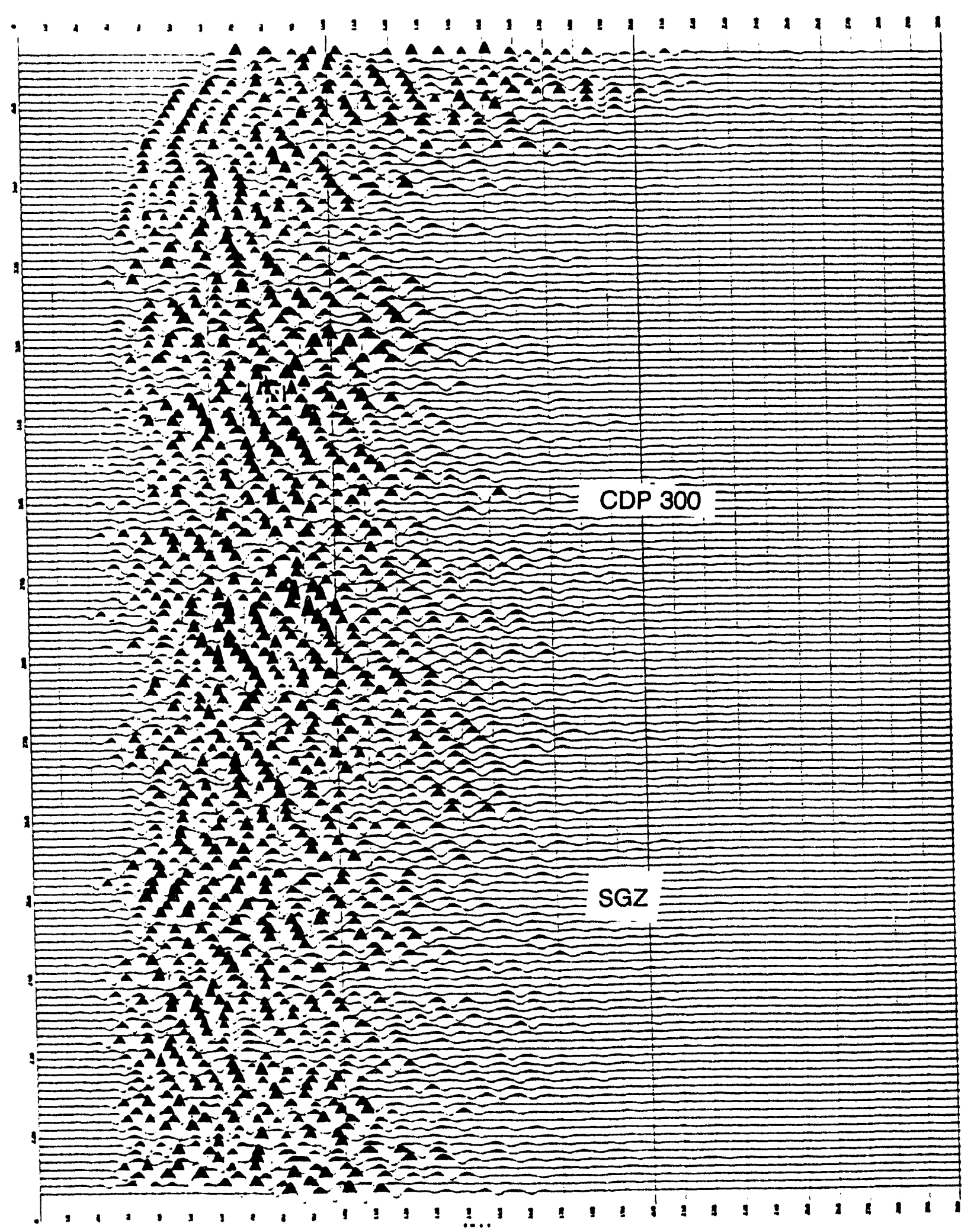




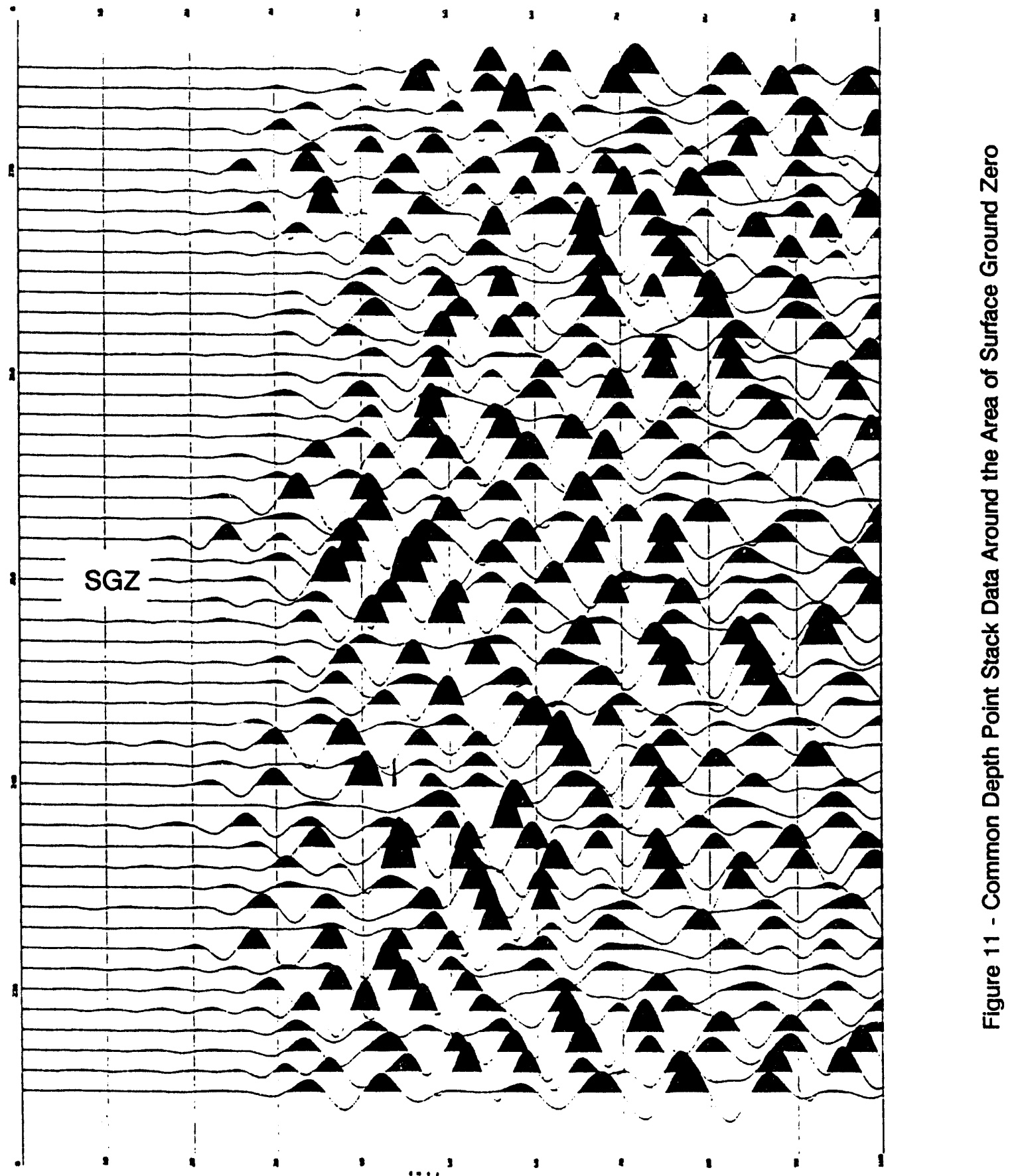


A second survey with a wider reflection angle was also conducted at the Piledriver location. This survey had a variable near offset ranging from 355 feet to 120 feet. This was achieved by leaving the farthest two sets of geophones ( 24 geophones / set) in place while varying the distance to the source. However, because the source was unable to negotiate the slope, the results after CDP stacking are mainly off the target as shown in Figure 12. These records do, however, show continuous reflection over hundreds of feet. Also favorable is the absence of reflected signal in the vicinity of SGZ as shown in Figure 13. 
Figure 12 - Common Depth Point Stack of Wideangle Data

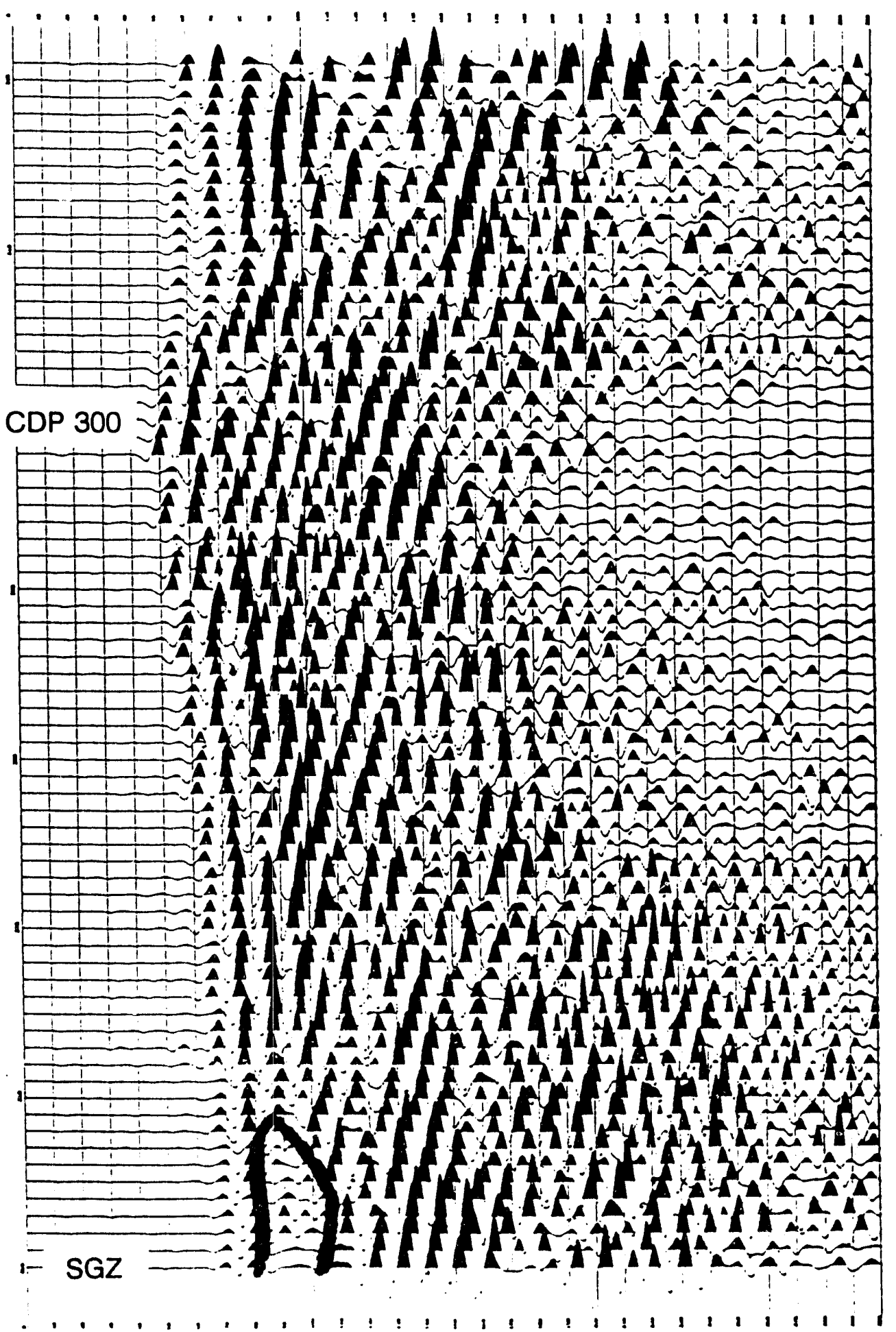




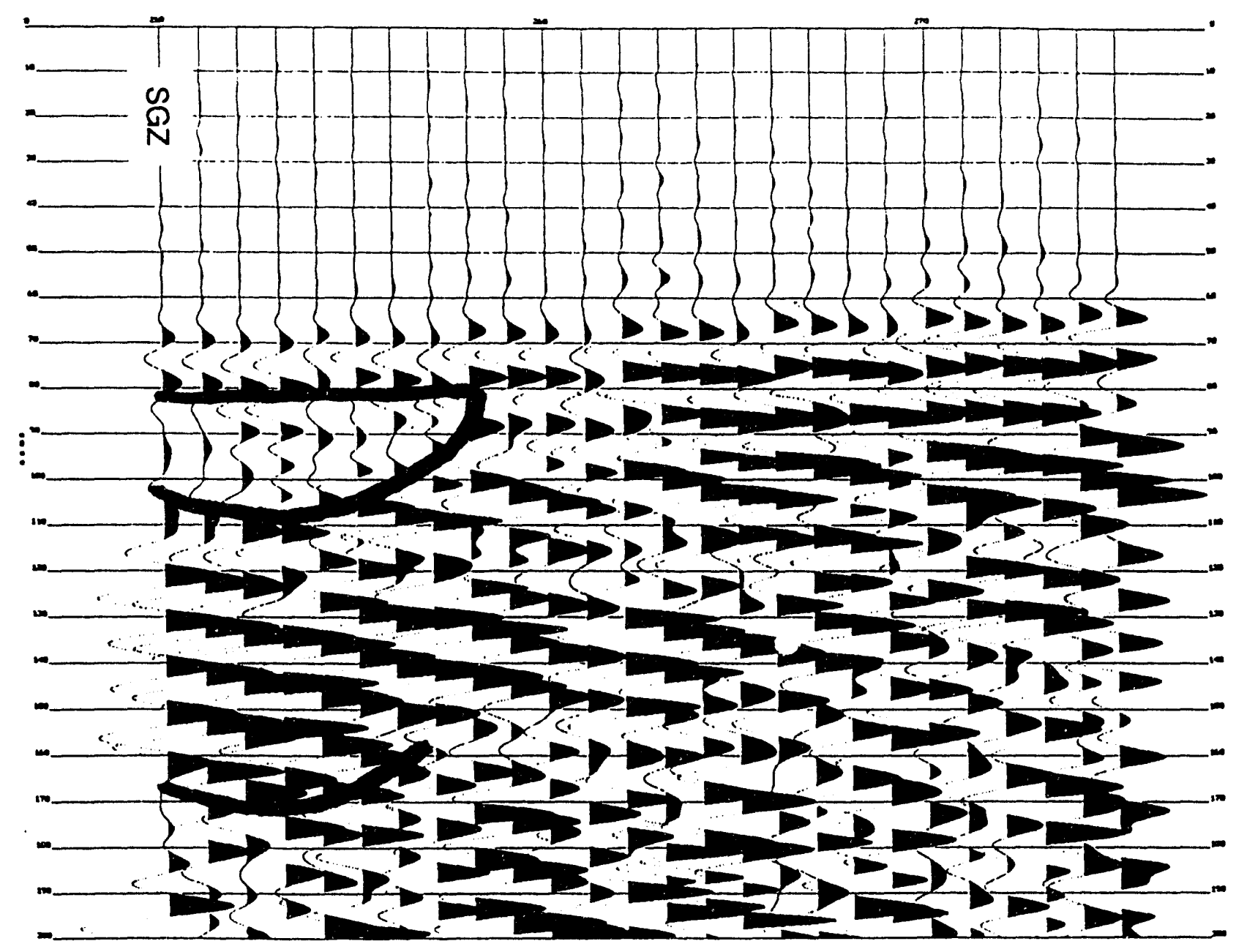

Figure 13 - Common Depth Point Stack of Wideangle Data Around the Area of Surface Ground Zero 


\subsection{RESULTS AND CONCLUSIONS}

\subsection{Results}

The requirement of the seismic survey was to analyze the chimney and void characteristics attributed to Piledriver. The first survey conducted was the only one which was designed prior to being in the field. It had a constant near offset of 50 feet. The second survey had a variable, longer offset which allowed for reflective signal to return to the geophones later than most waves attributed to interference.

The CDP stacked data obtained from the regular ( 50 foot) offset shows no sign of a reflector at all. When viewing the record specifically in the vicinity of $S G Z$, there is no sign of a reflector or even a disturbance anywhere near the known depth of the chimney.

The CDP stacked data from the wideangle (variable long offset) survey did, however, show signs of structure. Although the survey was started at the very edge of the "void body," there are some obvious signs of structure. In Figure 13, the reflector between 80 and 90 milliseconds is interrupted between CDP 250 and 258, corresponding to a depth of approximately $200 \mathrm{~m}$. Similarly, the ringing nature of the reflections (especially in the vicinity of CDPs 250 to 256) extends deeper than the surrounding areas, down to almost $430 \mathrm{~m}$. Considering CDP 250 to be the center of the structure, the width of the structure at the top is estimated as $25 \mathrm{~m}$.

\subsection{Conclusions}

The results, of course, leave much to be desired. The majority of time and effort in the field and lab was spent on the first, regular offset survey. Yet, no useful information could be derived from it. The wideangle survey analysis provides some better results although they too are somewhat vague. To this extent, when a survey is being referred to in the remainder of the 
conclusions, it is the wideangle survey, not the regular survey (unless otherwise noted).

One of the easiest arguments about any of the data is that if there was not previous knowledge of a cavity in existence, it probably would not have been noticed on these records. Some oddity is definitely present on the record, but its exact nature (whether void or structure) cannot be determined.

Secondly, the exact source of the multiple (or "ghost") reflections cannot be determined. The best explanation is spalling (splitting of the rock layers) caused by the initial detonation of Piledriver. Although typical estimates of fracturing due to nuclear explosions do not usually refer to fracture at such long distances from the ground zero (Boardman, 1966), it is not inconcelvable for such to occur, especially at a free surface in otherwise competent rock.

CDP stacking began at SGZ for the wideangle survey. This means that the first reflective "station" is directly above the center of the chimney structure which is being sought. Because the CDP stacking began at SGZ, no definite determinations can actually be made regarding how wide the found structure is. Note that the diameter estimated at the top of the chimney ( $25 \mathrm{~m}$, via the seismic survey) is only half that of the original pre-explosion chamber $(45 \mathrm{~m})$. According to drilling logs from the site, the diameter at the top of the chimney is slightly larger at the top than the bottom (Boardman, 1967). This means that either the region referred to as the top of the chimney is not actually the top, surface ground zero is not precise, or, the reflection survey did not pick up the full diameter of the chimney. Most likely, the actual reason is the third suggestion.

Although no reflections are visible at the depth of about $190 \mathrm{~m}$ (the known top of the chimney), the absence of a reflector at $200 \mathrm{~m}$ is very close, given available velocity information. At the same time, most surveying methods (especially one which is required so precise as for nuclear 
weapons testing) would not have an error as large as one meter, let alone $20 \mathrm{~m}$. It should also be noted that the most probable reason for no reflector at the very top of the cavity is diffraction (dispersion at nearly random angles) of the incoming seismic signal. If the apical void were an almost flat structure as suggested by previous drilling programs, the survey would not have encountered any problems in receiving reflections. If, however, the structure is more spherical than previously assumed (as would be suggested by considering the most stable cavity forming conditions), this not only could cause the void present in the record, but could have also added to the "noise" around the target area.

On the lower end of the record, the ringing nature of the reflection in the vicinity of SGZ extends down to about $430 \mathrm{~m}$. This number corresponds reasonably well to the given depth of about $460 \mathrm{~m}$ to the bottom of the chimney structure, thus indicating that while lateral extent may not be determined reliably, vertical interpretations can.

\subsection{Recommendations}

The wideangle survey provided the largest amount of useable information, therefore, this method should be used again concentrating on the area immediately surrounding SGZ. By centering the survey directly over SGZ, most uncertainties regarding the extent of the target will be eliminated. A wider-angle (than the one performed with this report) survey would also further reduce interference of surface waves in the record.

Because of tape usage considerations and possible system error during correlation, it would be best to use a small explosive source which could provide ample high frequencies and strengih. It would be more economical and also be faster both in actual recording and in correlation. The elimination of correlation would result in the elimination possible systematic errors, and, reduced tape consumption and required record length. 
To further reduce the cost and time of data acquisition, the surveys do not need to be extended so far from SGZ. The record need only have the region immediately surrounding SGZ, possibly 40 stations on either side (in a linear array). This would reduce the number of times the source is required to operate, the amount the equipment is to be moved and the amount of tape consumed.

Because the CDP stacks showed multiples of reflectors, further research should be done regarding the effects of free-surface spalling from underground nuclear blasts in competent rock, and the effect of minor fracturing on seismic wave velocitles. Sjфgren et al. (1979) has shown that definite correlations do exist between fracturing and wave velocity although their relationships (applied to such large explosions and complex fracturing relationships) may not correspond well. In addition, a downhole seismic velocity record would prove very useful in both proving / disproving Sjфgren's relationships and processing the data from all of the seismic reflection surveys.

To qualify the idea that the top of the chimney (in the area of the apical void) is more spherical than flat, previous sites which were explored via drilling should have their data reexamined. If not, a number of parallel seismic reflection survey lines could be conducted in the vicinity of SGZ. This three-dimensional picture may help better define the actual shape of the apical void.

Overall, seismic reflection is a very useful tool, however, its application in this case was incorrectly applied in the initial survey and incorrectly designed in the wideangle survey. Great care must be taken to provide ample energy while at the same time not to allow surface waves to dominate the record and obscure the results. 
References

Almossawi, H.I.H., 1988, Seismic Modelling: High-Frequency Range, Geophysical Prospecting, 36, 719-732.

Anonymous, 1986, US Underground Atomic Test Flops, New Scientist, 110 (1507), 22.

Boardman, C.R., 1966, Some Characteristics of the Hardhat Chimney and Surrounding Wall Rock: Livermore, Lawrence Radiation Laboratory, UCRL-50177.

Boardman, C.R., 1967, Results of an Exploration into the Top of the Piledriver Chimney: Livermore, Lawrence Radiation Laboratory, TID-4500, UC-35.

Burger, H.R., 1992, Exploration Geophysics of the Shallow Subsurface: Englewood Cliffs, Prentice Hall.

Butler, Dwain K., 1984, Microgravity and Gravity Gradient Techniques for detection of Subsurface Cavities, Geophysics, 49, 1084-1096.

Casten, U. and C. Gram, 1989, Recent Developments in Underground Gravity Surveys, Geophysical Prospecting, 37, 73-90.

Didwall, E.M. and C.G. Dease, 1984, Numerical and Experimental Results for Detection of Underground Voids Using Controlled Electromagnetic Technique, Geophysics, 49, 606.

Dresen, L. and R. Elsen, 1982, Locating and Mapping of Abandoned Mine Shafts at Shallow Depths by Engineering-Geophysical Methods, Geophysics, 47, 417.

Gerety, M., J. Nyhan and R. Oliver, 1989, History and Geophysical Description of Hazardous Waste Disposal Area A Technical Area 21: Los Alamos, Los Alamos National Lab, LA-11591-MS,

Greaves, R.J., 1985, Coal Prospect Evaluation Using High-Resolution Reflection Seismology: A Case Study, Mining Engineering, 37, 1061-1064.

Habberjam, G.M. and J.T.Whetton, 1952, On the Relationship Between Seismic Amplitude and Charge of Explosive Fired in Routine Blasting Operations, Geophysics, 17, 116-128.

Hagemann, R.F., 1982, High-Resolution Reflection Seismic Including Three-Dimensional Techniques: A Review of the State of the Art, Geophysics, 47, 415.

Hunter, J.A., S.E. Pullan, R.A. Burns, R.M. Gagne and R.L. Good, 1984, Shallow Seismic Reflection Mapping of the Overburden-Bedrock Interface with the Engineering Seismograph- Some Simple Techniques, Geophysics, 49, 1381-1385.

Knapp, R.W., D.W. Steeples, T.W. Stander, D.A. Kopsick and B.J. Heckendorn, 1983, Seismic Reflection Profiling of a Hazardous Waste Site: A Case Study of Shallow, High Resolution Data Acquisition, Processing and Analysis, Geophysics, 48, 804. 
Knapp, R.W. and D.W. Steeples, 1986, High Resolution Common-Depth-Point Seismic Reflection Profiling: Instrumentation, Geophysics, 51, 276-282.

Krohn, C.E., 1984, Geophone Ground Coupling, Geophysics, 49, 722-731.

Leet, L.D., 1946, Earth Motion from the Atomic Bomb Test, American Scientist, 34, 198-211.

Mair, J.A. and A.G. Green, 1981, High Resolution Seismic Reflection Profiles Reveal Fracture Zones Within a 'Homogeneous' Granite Batholith, Nature, 294, 439-442.

Miller, R.D. and D.W. Steeples, 1992, Seismic Reflection Surveys Before and After Bexar at the Nevada Test Site: Los Alamos, Los Alamos National Laboratory, LAUR-92-244.

Miller, R.D., S.E. Pullan, D.W. Steeples and J.A. Hunter, 1989, Field Comparison of Shallow Seismic Sources Near Chino, California: Lawrence, Kansas Geological Survey.

Miller, R.D., S.E. Pullan, J.S. Waldner and F.P. Haeni, 1986, Field Comparison of Shallow Seismic Sources, Geophysics, 51, 2067-2092.

Nelson, R.G., 1982, Seismic Reflection and Mineral Prospecting, American Association of Petroleum Geologists Bulletin, 66, 977-978.

Olhoeft, G.R., 1986, Direct Detection of Hydrocarbon and Organic Chemicals with Ground Penetrating Radar and Complex Resistivity, Proceedings of the National Water Well Association Conference on Petroleum Hydrocarbons and Organic Chemical in Ground Water, Houston, Texas, p 1-22.

Ringdal, F., P.D. Marshall and R.W. Alewine, 1992, Seismic Yield Determination of Soviet Underground Nuclear Explosions at the Shagan River Test Site, International Journal of Geophysics, 109, 65-77.

Rüter, H. and R. Schepers, 1985, Is It Possible to Increase the Resolution in Seismic Exploration for Coal by Using High Frequency Signals, Geophysical Prospecting, 33, 1160-1173.

Sjфgren, B., A. Фfthus and J. Sandberg, 1979, Seismic Classification of Rock Mass Qualities, Geophysical Prospecting, 27, 409-442.

Steeples, D.W., 1984, High Resolution Seismic Reflections at $200 \mathrm{~Hz}$, Oil and Gas Journal, (Dec 3), 86-92.

Tsuneo, I., S. Toshihiko and T. Kanemori, 1987, Use of Ground-probing Radar and Resistivity Surveys for Archeological Investigations, Geophysics, 52, 137-150.

Wu, B., M.S. King and J.A. Hudson, 1991, Stress-induced Llirasonic Wave Velocity Anisotropy in a Sandstone, International Journal of Rock Mechanics, Mining Science \& Geomechanical Abstracts, 28, 101-107.

Ziolkowski, A. and W.E. Lerwill, 1979, A Simple Approach to High Resolution Seismic Profiling for Coal, Geophysical Prospecting, 27, 360-393. 


\section{Bibliography}

Archambeau, C.B., 1986, Verifying a Test Ban: A New Approach to Monitoring Underground Nuclear Tests, Issues in Science and Technology, 2 (2), 18-19.

Borg, I.Y., 1973, Extent of Pervasive Fracturing Around Nuclear Explosions, International Journal of Rock Mechanics and Mining Sciences, 10, 11-18.

Carter, B.J., E.Z. Lajtai and A. Petukhov, 1991, Primary and Remote Fractures Around Underground Cavities, International Journal for Numerical and Analytical Methods in Geomechanics, 15, $21-40$.

Douglas, A. and J. A. Hudson, 1990, The Effect on Teleseismic $P$ of the Zone of Damage Created by an Explosion, International Journal of Geophysics, 103, 111-113.

Gochioco, L.M. and S.A. Cotten, 1989, Locating Faults in Underground Coal Mines Using HighResolution Seismic Reflection Techniques, Geophysics, 54, 1521-1527.

Haeni, F,P., 1981, High Resolution Seismic Reflection Methods and Their Application to Hydrologic Studies in Connecticut and Florida, Ground Water, 19, 445.

Henson, H. and J. L. Sexton, 1991, Premine Study of Shallow Coal Seams Using High-Resolution Seismic Reflection Methods, Geophysics, 56, 1494-1503.

Horgan, J., 1986, Underground Nuclear Weapons Testing, IEEE Spectrum, 23, 32-43.

Key, S. C. and S. B. Smithson, 1990, New Approach to Seismic Reflection Event Detection and Velocity Determination, Geophysics, 55, 1057-1069.

Lajtai, E.Z. and V.N. Lajtai, 1975, The Collapse of Cavities, International Journal of Rock Mechanics, Mining Sciences and Geomechanical Abstracts, 12, 81-86.

Lambiase, J.J. and J.K. Costain, 1981, Evaluation of Atlantic Coastal Plain Geothermal Reservoirs Using Seismic Reflection Data, American Association of Petroleum Geologists Bulletin, 65, 946-947.

Lericolais, G., J.P. Allenou, S. Berné and P. Morvan, 1990, A New System for Acquisition and Processing of Very High-Resolution Seismic Reflection Data, Geophysics, 55, 1036-1046.

Lindseth, R. O., 1982, Digital Processing of Geophysical Data; A Review: Tulsa, Soclety of Exploration Geophysics.

Milkereit, B., H. Stümpel and W. Rabbel, 1986, Shear-Wave Reflection Profiling for Near Surface Lignite Exploration, Geophysical Prospecting, 34, 845-855.

Miller, R.D. and D.W. Steeples, 1986, Shallow Structure from a Seismic-Reflection Profile Across the Borah Peak, Idaho, Fault Scarp, Geophysical Research Letters, 13, 953-956.

Perret, W.R., 1972, Gasbuggy Selsmic Source Measurements, Geophysics, 37, 301-312. 
Ross, H.P., W.E. Glenn and C.M. Swift, 1981, Reflection Seismic Surveys for Basin and Range Geothermal Areas- An Assessment, American Associatlon of Petroleum Geologists Bulletin, 65, 982.

Ruskey, F. and L. Snyder, 1982, Seismic and Resistivity Techniques for Locating Abandoned Coal Mine Workings, Geophysics, 47, 415-416.

Singh, S., 1984, High-Frequency Shallow Seismic Reflection Mapping in Tin Mining, Geophysical Prospecting, 32, 1033-1044.

Steeples, D.W., R.W. Knapp and C.D. McElwee, 1986, Selsmic Reflection Investigations of Sinkholes Beneath Interstate Highway 70 in Kansas, Geophysics, 51, 295-301.

Telford, W.M. et al., 1990, Applied Geophysics, 2nd ed., Cambridge, Cambridge University Press.

Werth, G.C. and R.F. Herbst, 1963, Comparison of Amplitudes of Seismic Waves from Nuclear Explosions in Four Mediums, Journal of Geophysical Research, 68, 1463-1475.

Widess, M.B., 1973, How Thin is a Thin Bed, Geophysics, 38, 1176-1180.

Yilmaz, O., 1987, Seismic Data Processing, Tulsa, Society of Exploration Geophysics.

Young, R.P. and J.J. HIII, 1986, Seismic Attenuation Spectra in Rock Mass Characterization; A Case Study in Open-pit Mining, Geophysics, 51, 302-323. 


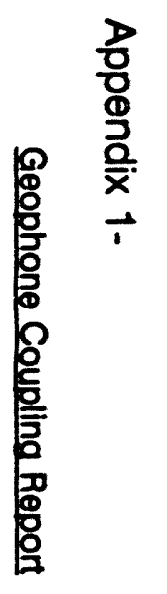




\title{
Geophone Coupling Experiment
}

\author{
at TA-49 \\ 30 June 1992
}

Report prepared by:

Karl E. Tonander, contractor

Now Mexico Institute of Mining and Technology

For:

Los Alamos National Laboratory, Group EES-3 
On 30 June 1992, at Los Alamos National Lab, Technical Area 49, tests were conducted to evaluate the best coupling method(s) for use in areas with highly attenuating medla (such as the Bandalier Tuff).

In order to properly evaluate the types of coupling in the field each station consisted of two geophones. Additionally, both a radial array (to evaluate local geologic affects on the experiment) and linear array (to evaluate the affects of distance) were used to evaluate the various coupling methods.

\section{Field Arrangements}

The set-up was designed so that five stations were in a semi-circle with a linear array of five stations leading away from this radial portion. The semi-circle was eight feet in radius centered around the source (hammer and plate). The linear stations were spaced at three foot intervals. In each case both a control and experimental phone were placed as close to each other as possible without having the experimental phone's planting method disturb the control phone. The use of the hammer and plate as a source was to provide sufficient energy to find shallow reflections known to be in the area while not obscuring them with ground roll.

\section{Economical Methods}

The coupling methods used in this experiment require less than $1 / 4$ of man-hour per phone and no supplies more sophisticated than water or a shovel. These are all methods which can be adopted on a caseby-case basis to improve survey results as needed.

The standard method of planting phones is to place them into the ground up to the top of the spike. The first modification to this method is to increase the length of the spike. The next step is to simply cover the phone with soil (or a sandbag). The third modification is to dig a shallow hole, plant the phone, and then bury it. Water can be used with any of these methods to improve very dry or unconsolidated media.

In the case of this particular experiment, no water was used, covered phones had the top of the phone covered by at least three inches of soil and buried phones had the top of the phone at least three inches below the surface. 
Results

The use of longer spikes improves signal strength slightly, but does not affect background noise to any measurable degree. The other two modifications both reduce high frequency signal noise (such as wind noise and air wave energy).

Channels 23 and 24 (the furthest from the source) are used as the common channels to establish the normal characteristics of the phones at this station. From Figure 1 it can be found that there is no significant difference between the reactions of the phones when both the control (channel 23) and the experimental (channel 24) are on the surface.

The covered phone does in fact produce less high frequency noise than the surface phone as shown in Figure 2. This is especially evident when viewing those records taken with a $100 \mathrm{~Hz}$ low cut filter applied, such as Figures 3 through 7 . Figures 3 and 4 are records of the last two stations (odd channels are surface planted, even channels are covered). In both cases, noise is more prominent on the records produced by the surface phones than the covered phones. A close-up of the tail section of the records, Figures 5 and 6, exemplifies this difference, while, a close-up of the initial portion of the record, Figure 7 shows a similar quieting behavior on the part of the covered phone.

Figure 8 shows an approximate 20 fold decrease in high frequency noise due to phone burial. $A$ closer look at the tail sections of two stations from the same record, Figures 8 and 9, reveals a much less distorted wave form from the buried phone. Also, similar to the covered phone records with the $100 \mathrm{~Hz}$ filter, high frequency noise is positively shown as being reduced when the phone is buried in Figures 10 and 11.

\section{Conclusions}

When the source is strong and environmental conditions are not adverse (windy), or, when doing refraction studies where high frequency energy is not necessarily important, conventional surface geophone planting is the quickest easiest method. For surveys requiring a strong high frequency signal and a good signal-to-noise ratio, covering the geophones is an economical method of sufficiently improving coupling. In regions of particularly bad surface material or where high frequency signal clarity is especially critical, geophone burial is the preferred method. 
Figure 1

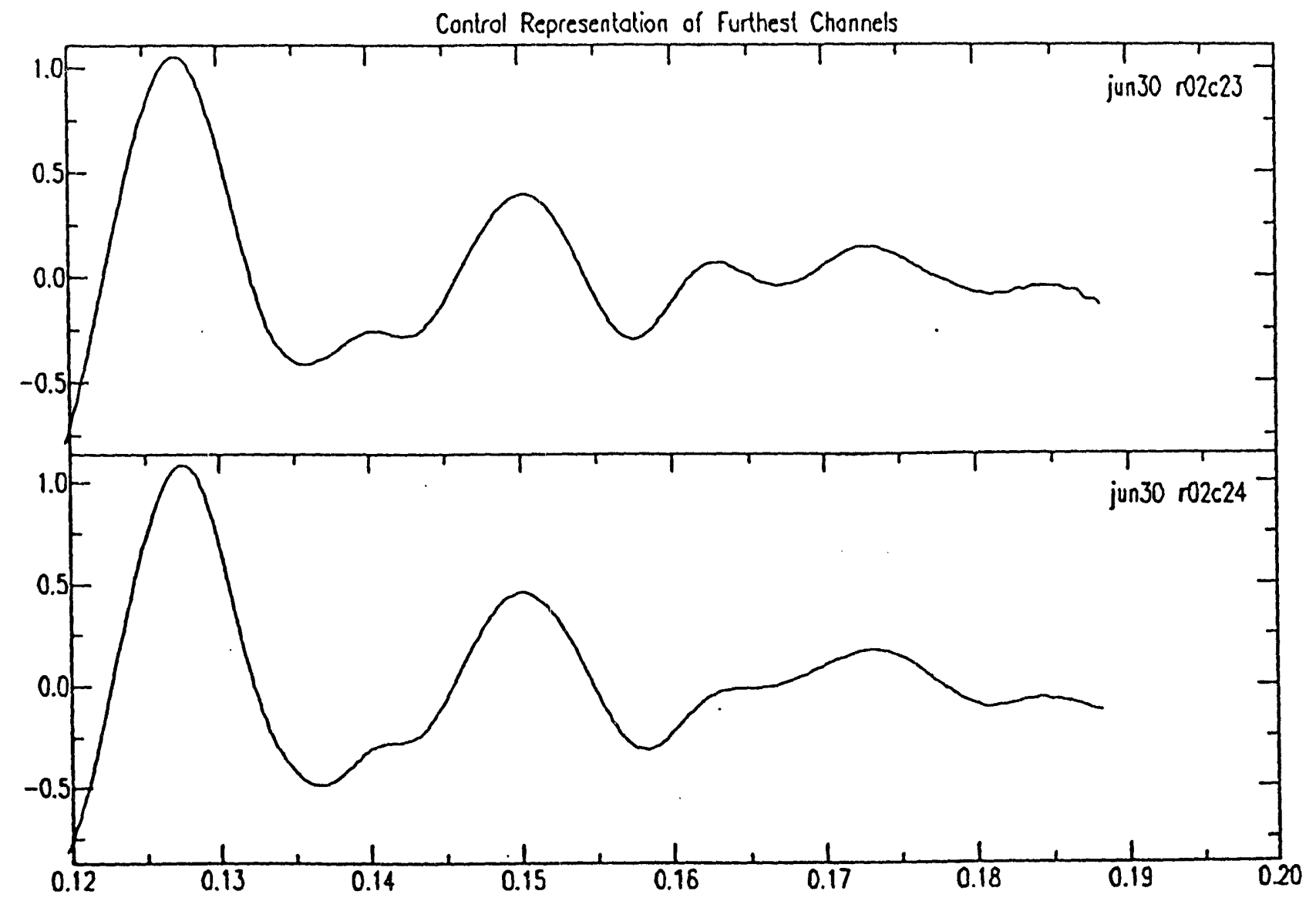


Figure 2

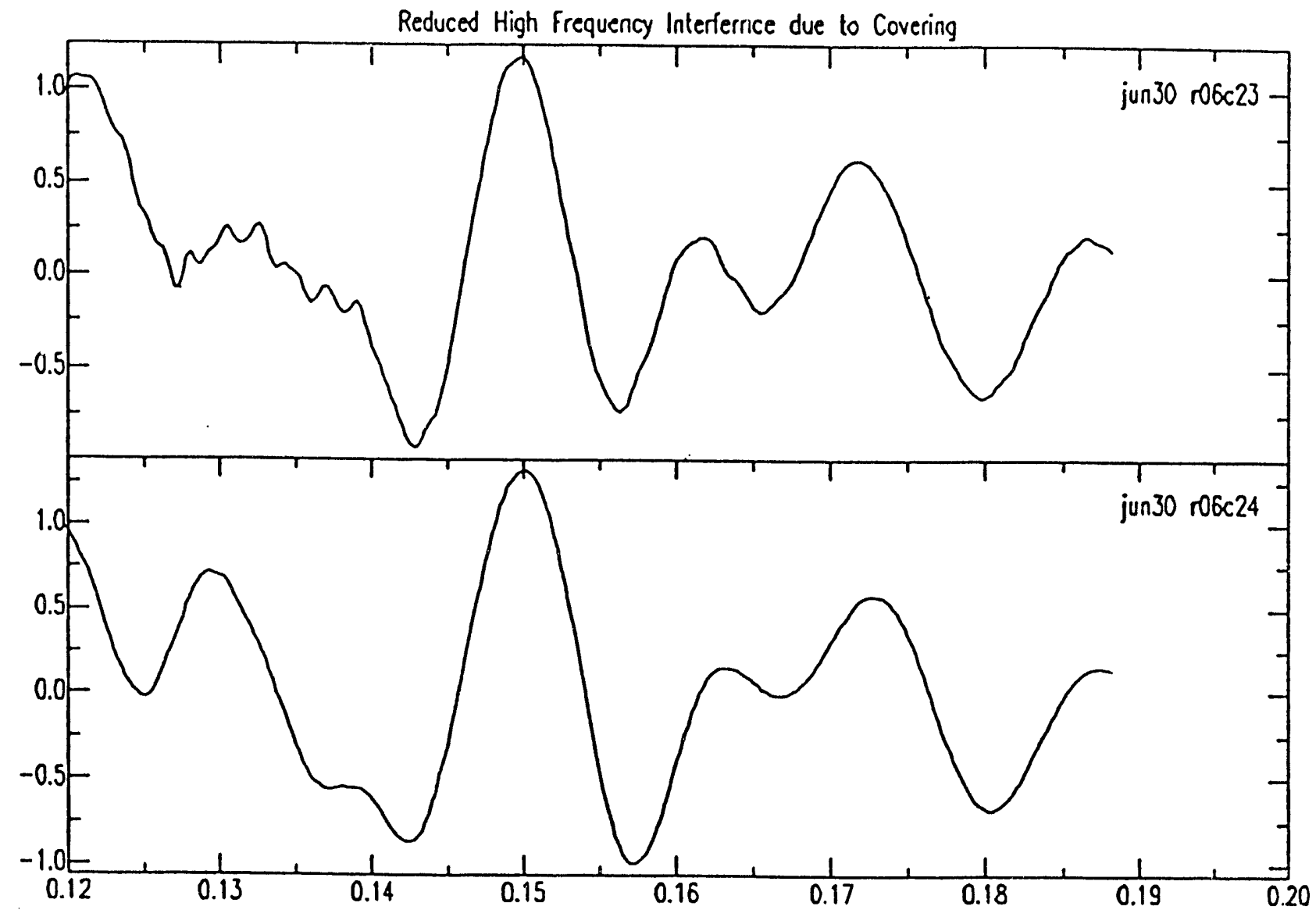


Figure 3

Reduced Noise due to Covering on $100 \mathrm{~Hz}$ Lowcul Records

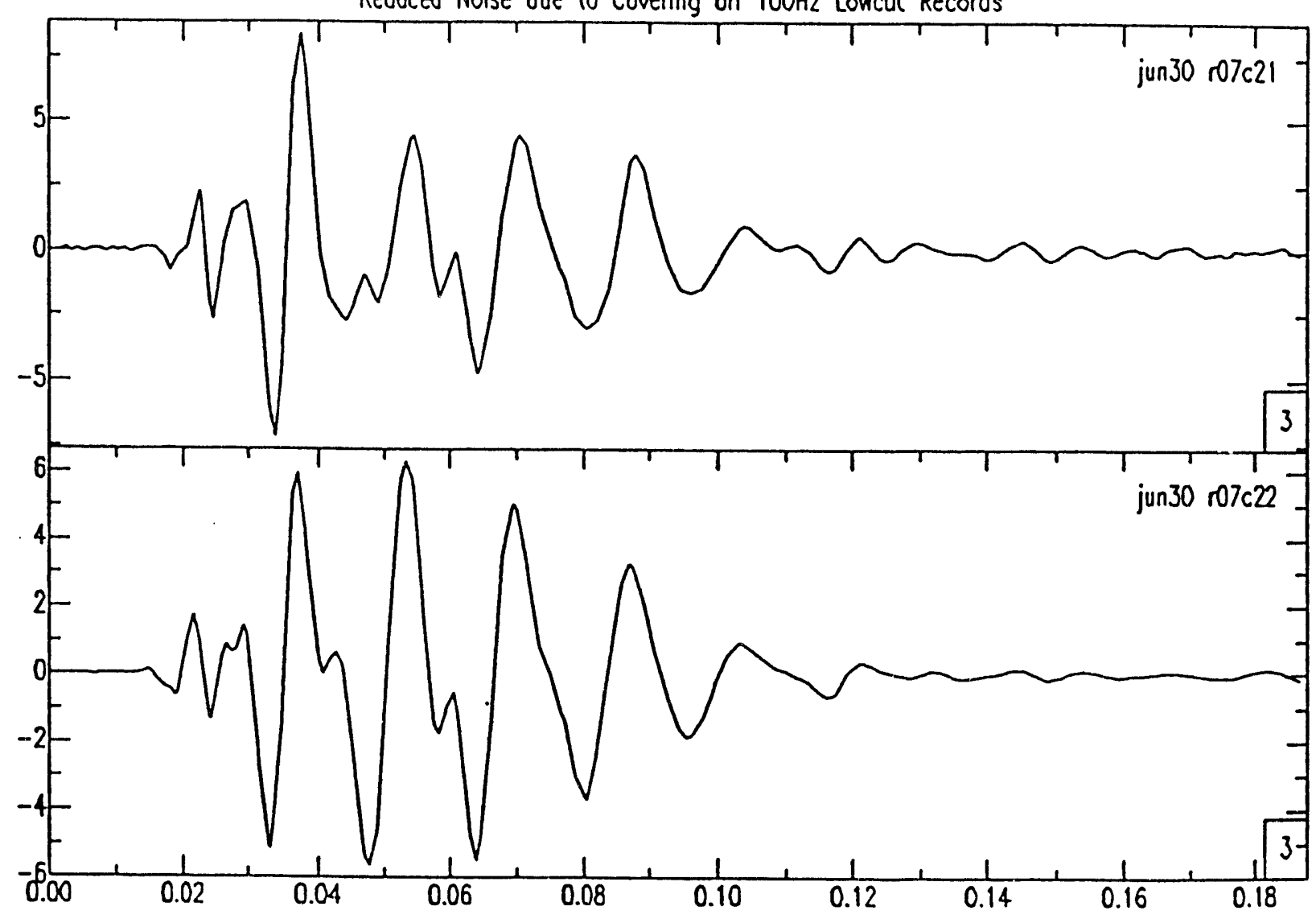


Figure 4

Reduced Noise due to Covering on $100 \mathrm{~Hz}$ Lowcut Records

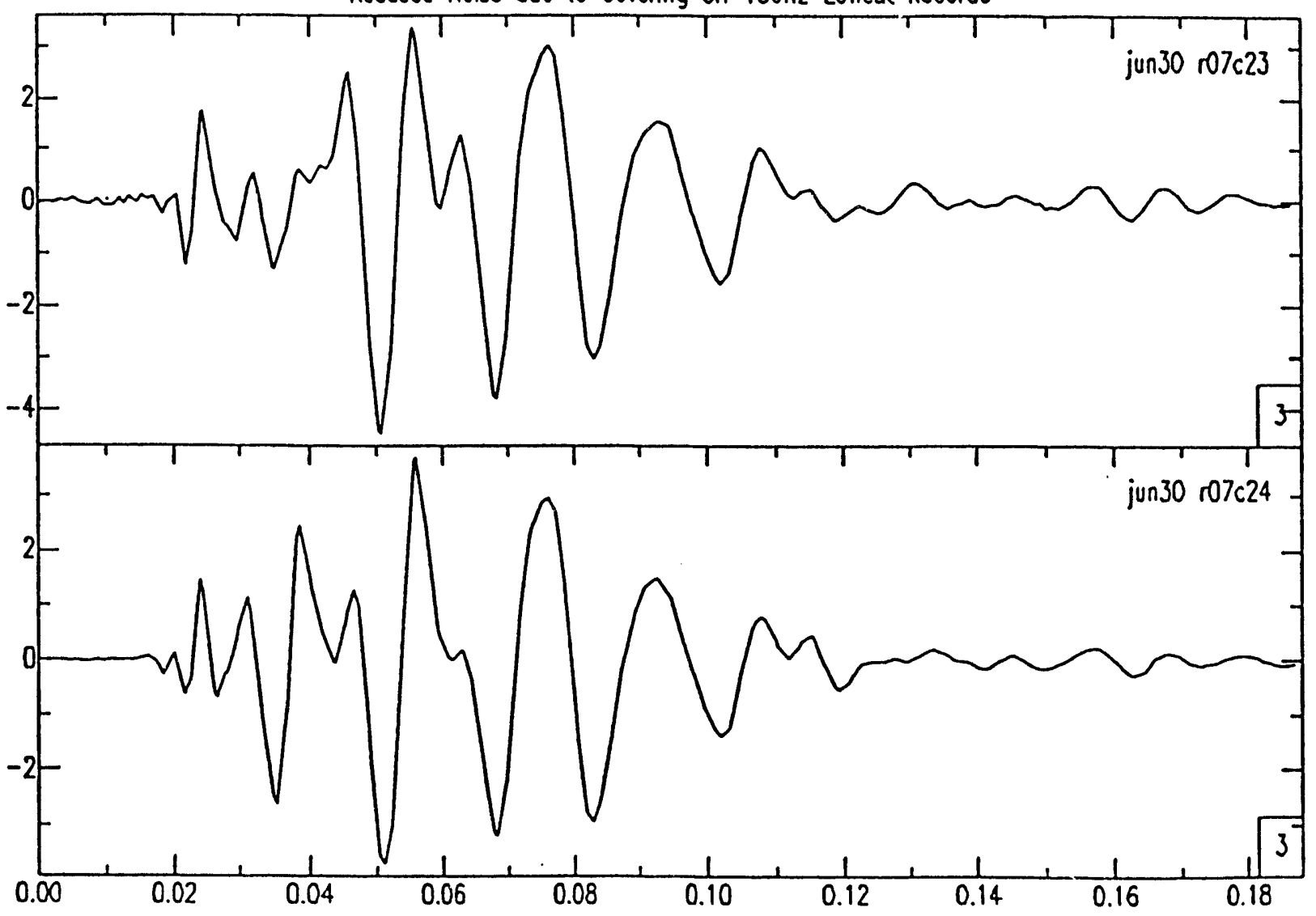




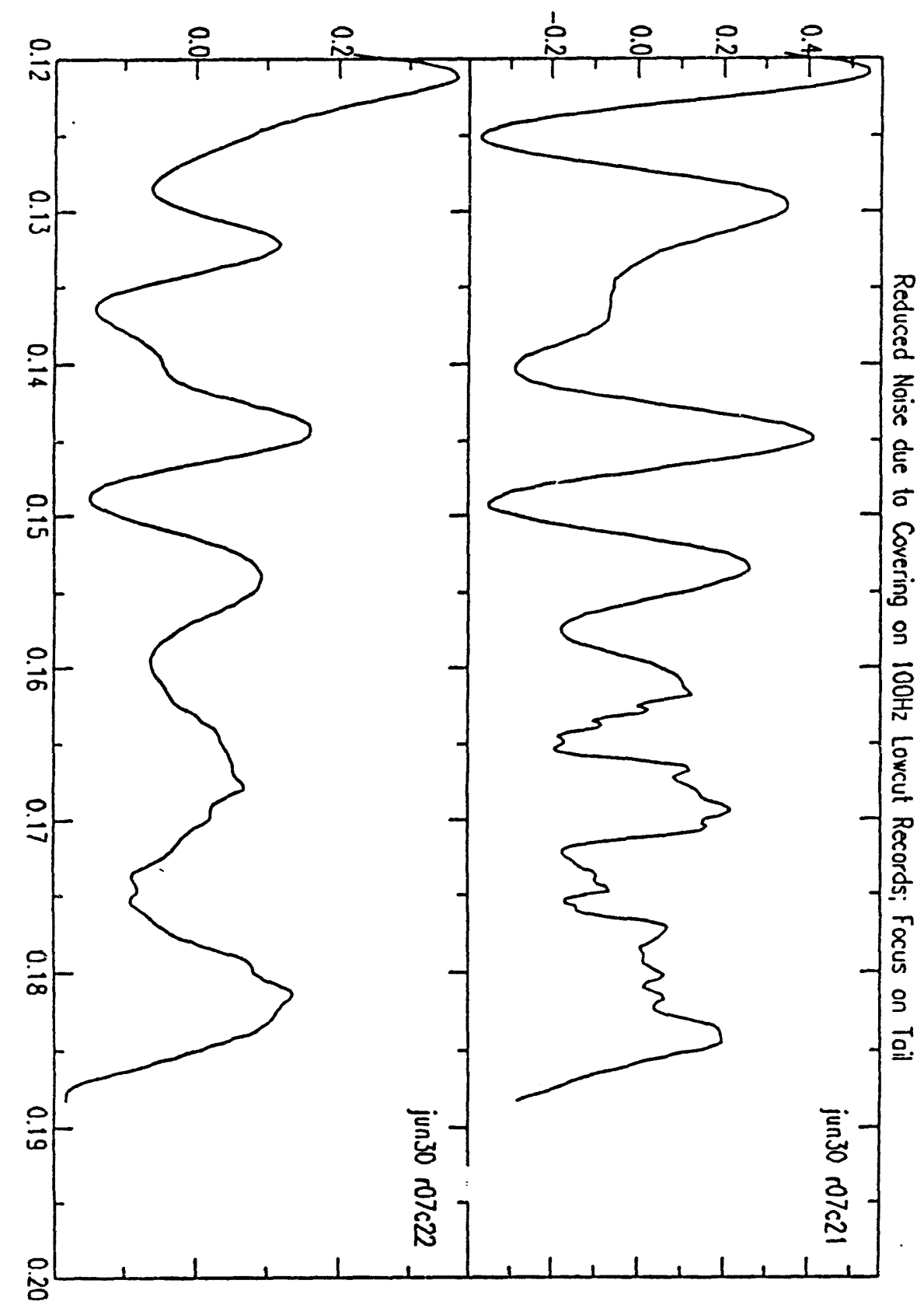

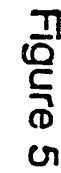




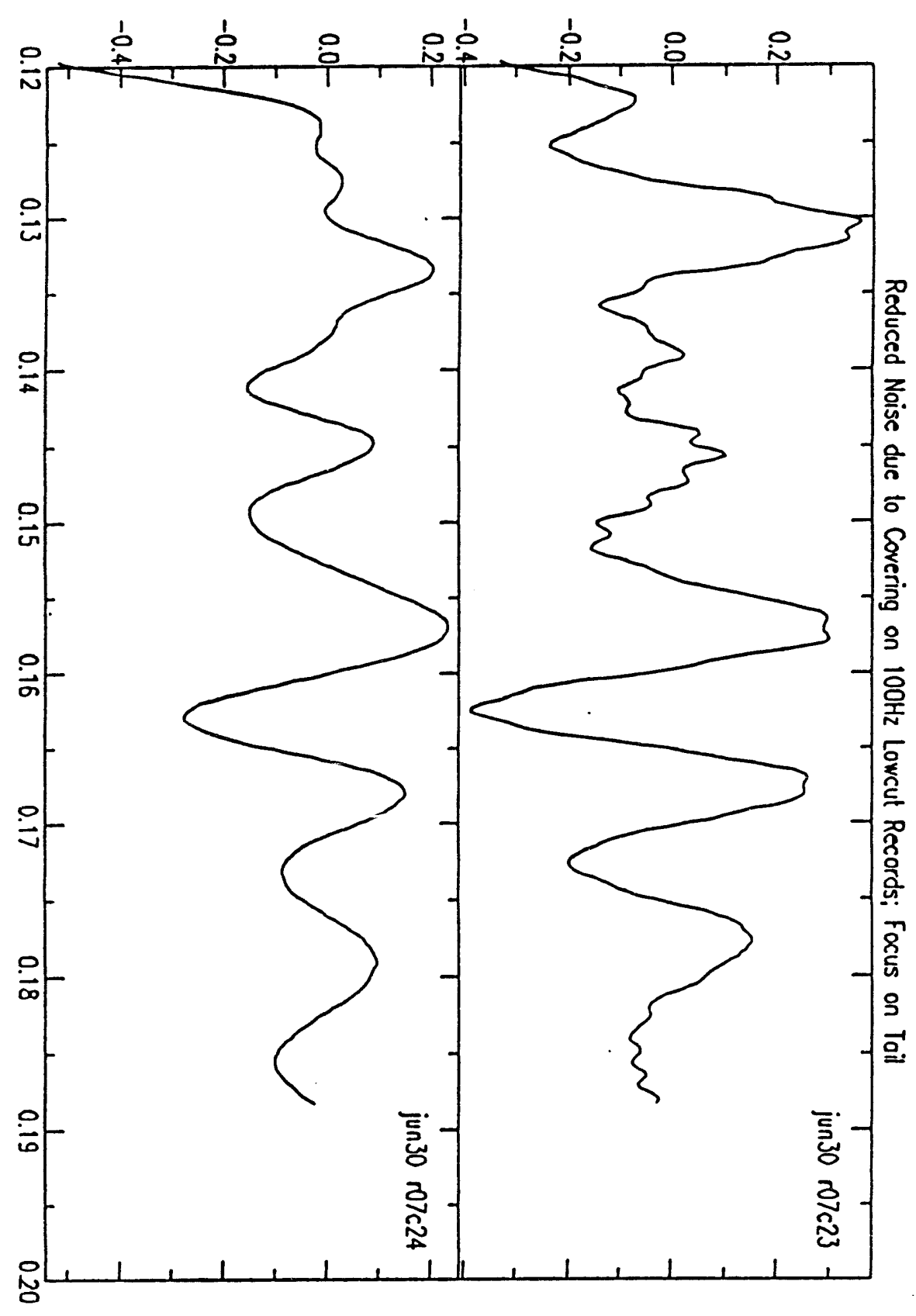

Th
음
0
0
0 
Figure 7

Reduced Noise due to Covering on $100 \mathrm{~Hz}$ Lowcul Records; Focus on Iniliotion

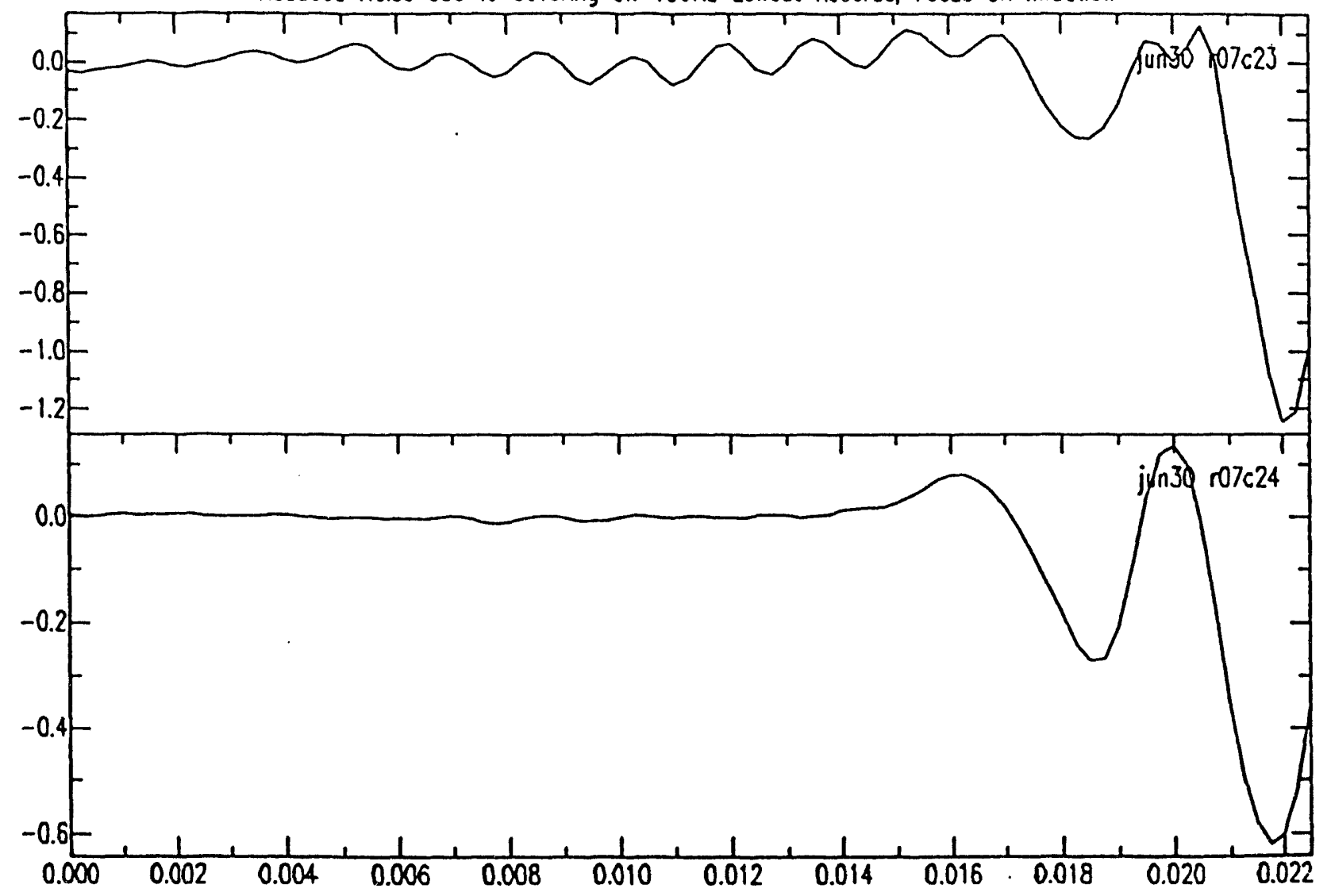


Figure 8

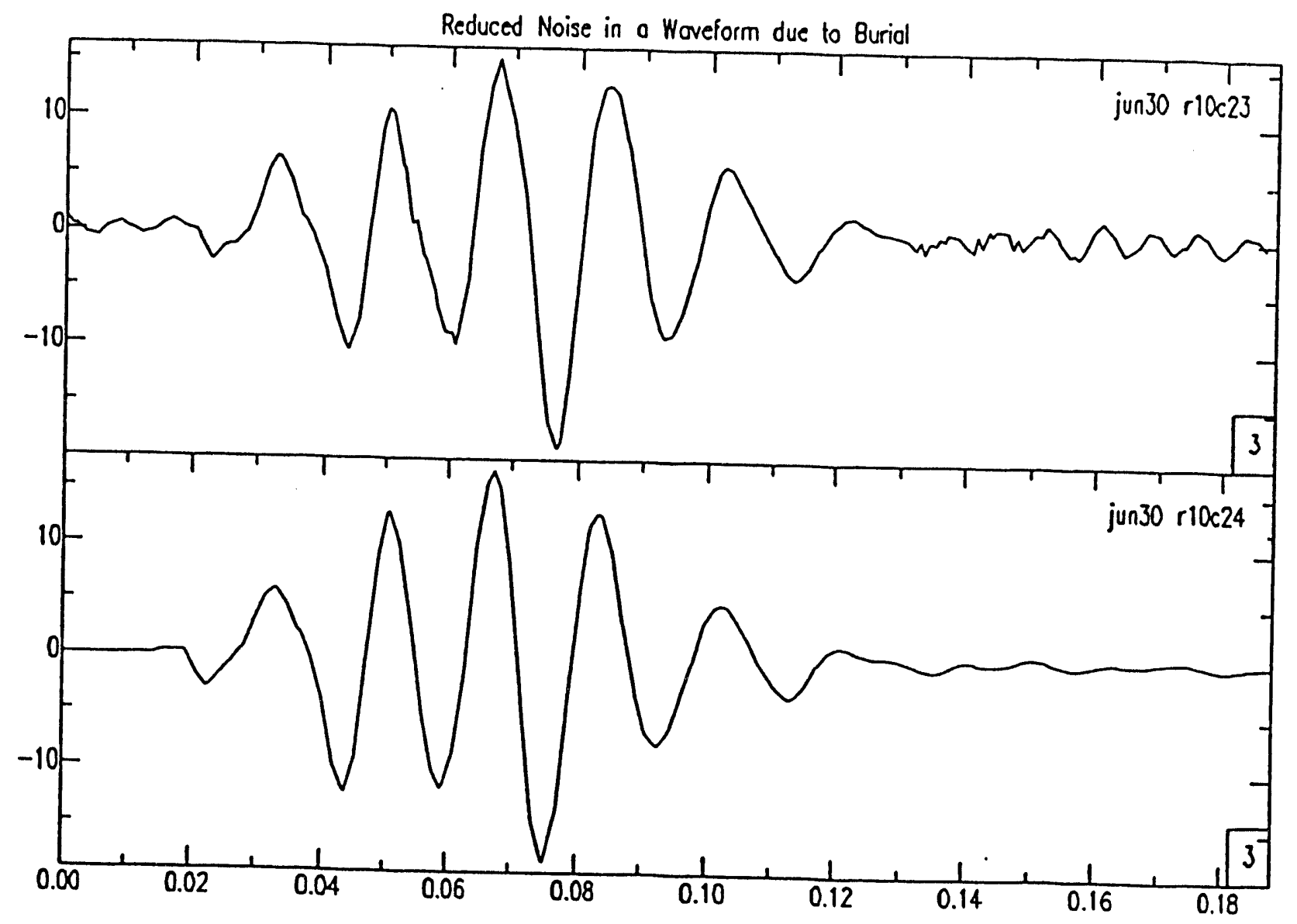


Figure 9

Reduced Noise in o Waveform due to Burial; Focus on Tail

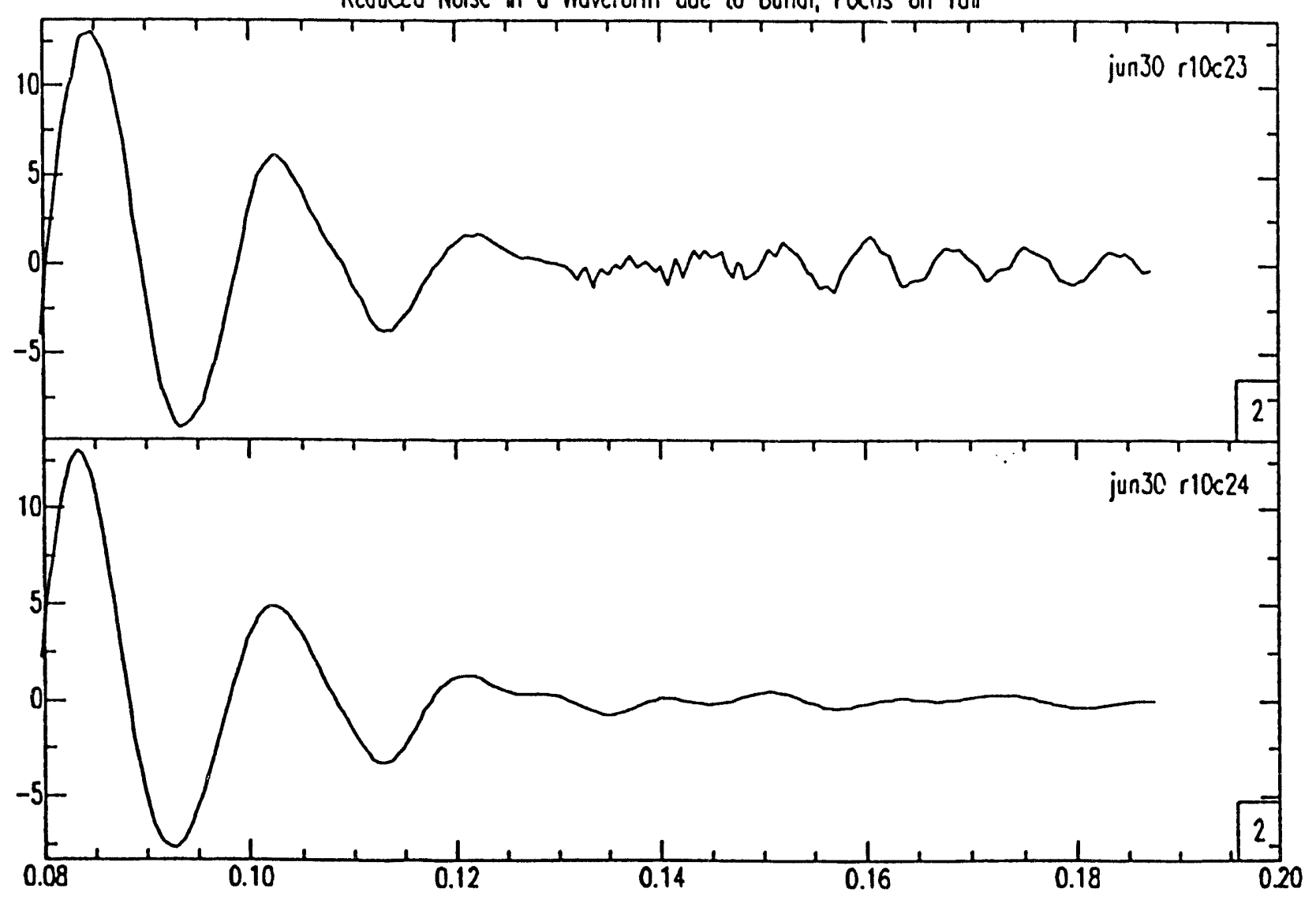


Figure 10

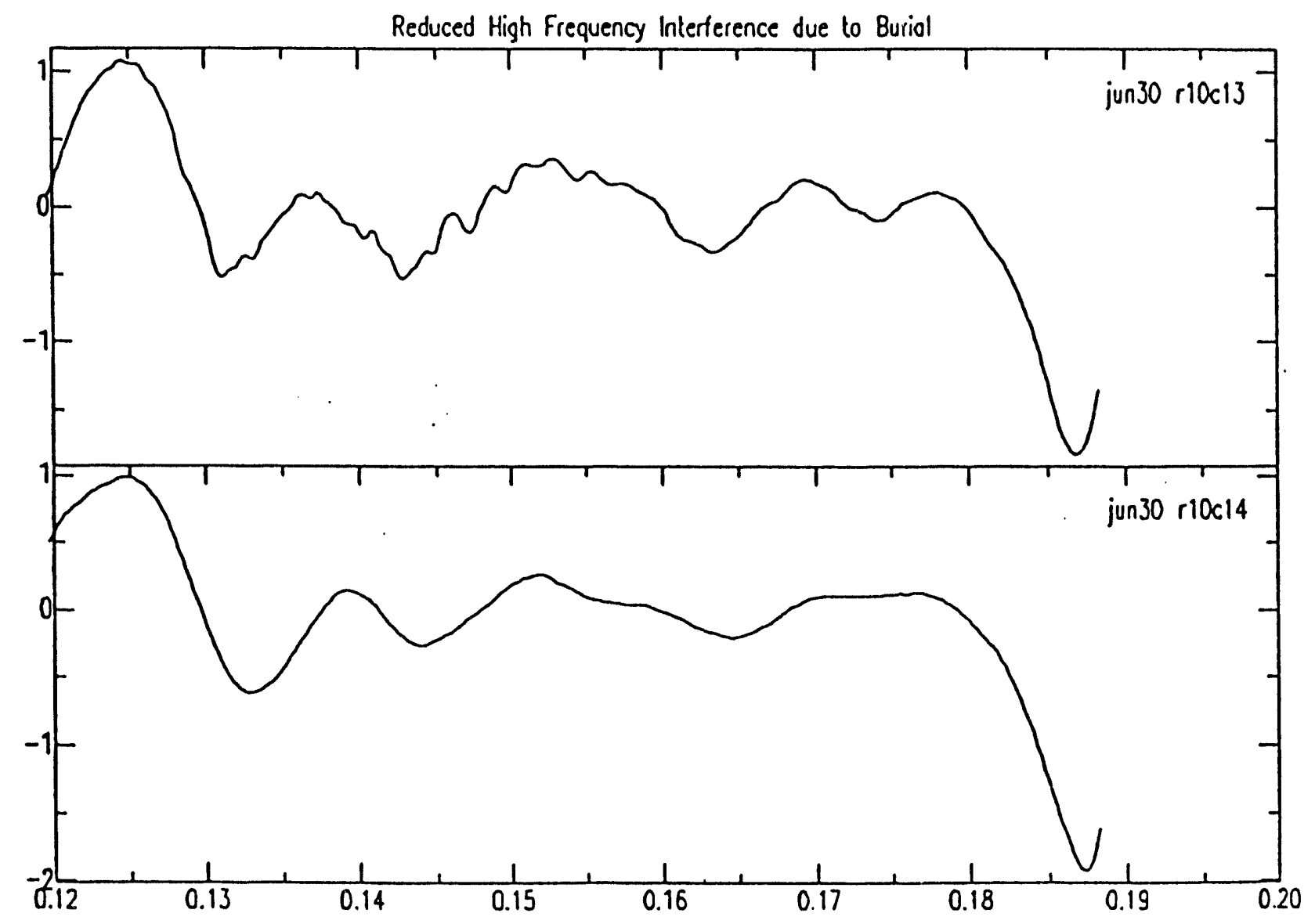




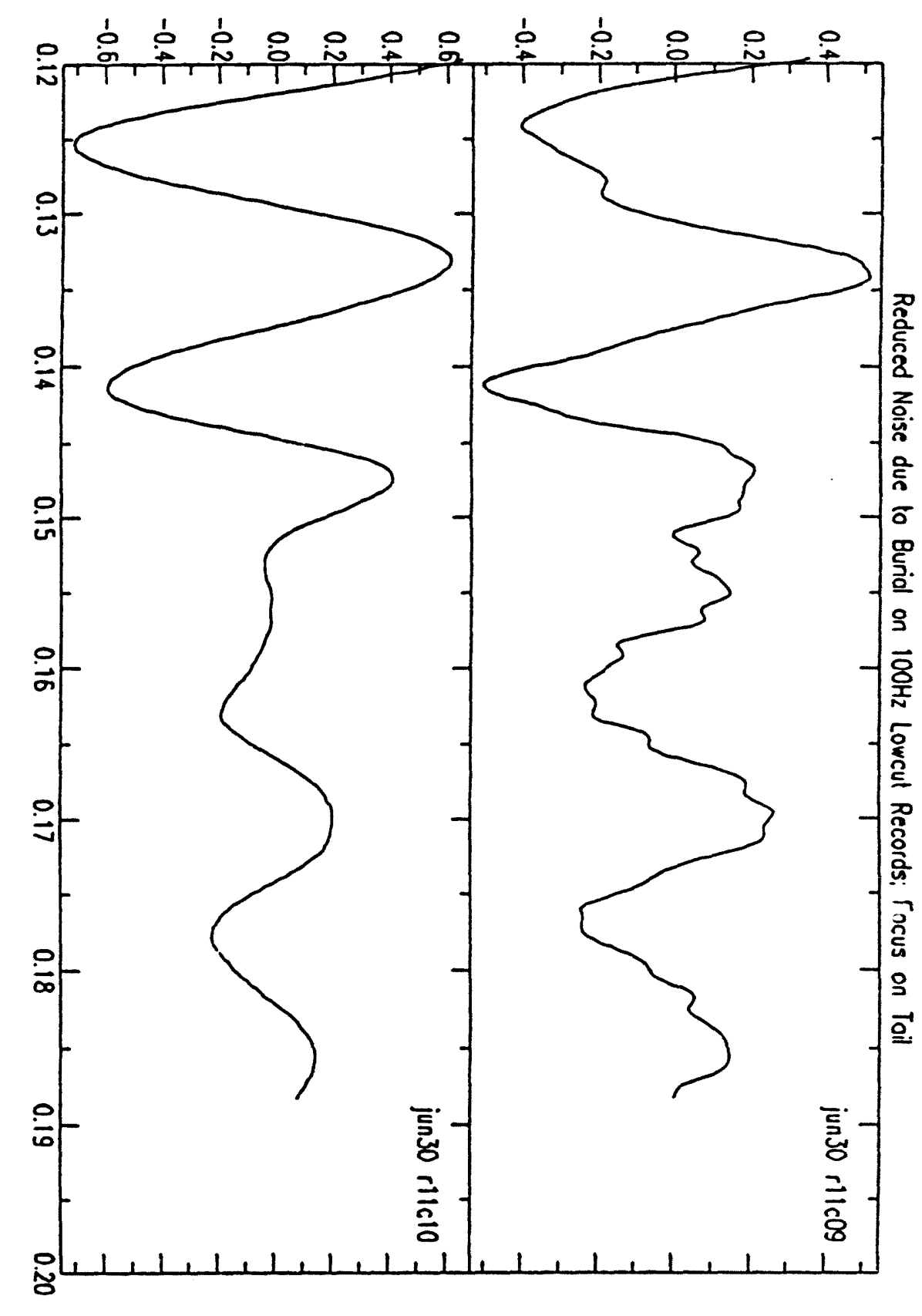




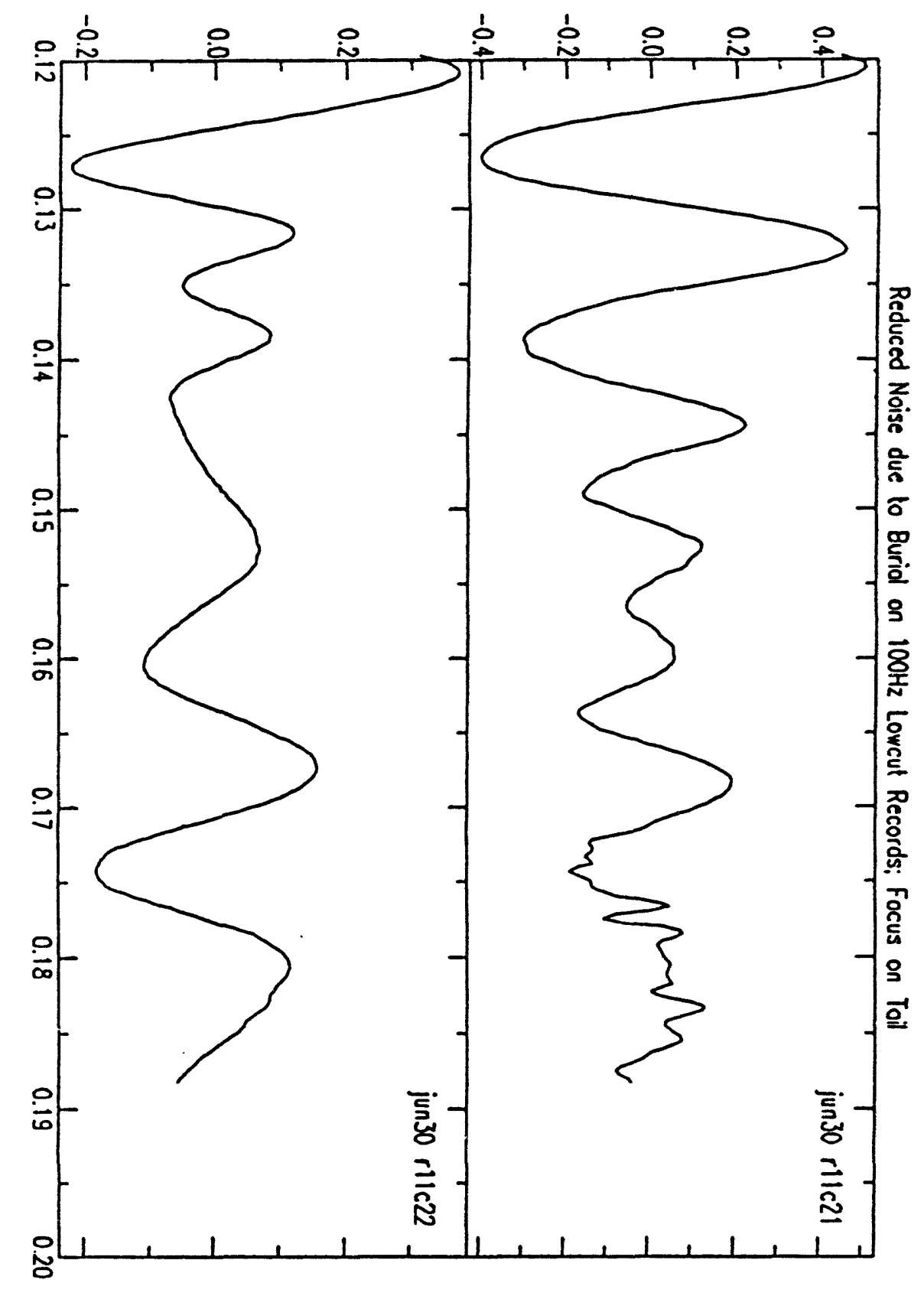

끔
$\frac{1}{\overline{0}}$
N 
Appendix 2-

EG\&G ES2420 Digital Reflection Seismegraph Specifications 
EG\&G ES2420 Digital Reflection Seismograph

Analog Specifications

Preamplifier Gain:

Input Inpedance:

Maximum Differential Voltage:

Low Cut Filter:

Type:

Frequency:

Notch Filter:

Attenuation Slope:

Frequency:

Diaitizer Specifications

Mantissa:

Exponent:

Gain Step Relative Accuracy:

A/D Converter Accuracy:

A/D Converter Linearity:

System Response Specifications

Useable Signal to Noise Ratio:

Frequency Response:

Gain Accuracy:

Gain Similarity Between Channels:

Total Harmonic Distortion:

Crossfeed:

Timing:

Sample Skew:
$30.1,36.1$, or $42.1 \mathrm{db}$

Differential, 20k ohms, 0.01 ufd

Common Mode, $5 \mathrm{k}$ ohms, 0.02 ufd

$0.640 \mathrm{~V}$ (@30.1 db), peak to peak

$0.320 V(@ 36.1 \mathrm{db})$

$0.160 \mathrm{~V}$ (@42.1 db)

Butterworth

5 to $320 \mathrm{~Hz}$ in $5 \mathrm{~Hz}$ Increments

$18 \mathrm{db} /$ octave

$50,60 \mathrm{~Hz}$ or Out (switchable)

15-bit ( +1 reserved for sign)

4-bit representing the gain range

$0.1 \%$

$0.2 \%$

$0.01 \%$

$100 \mathrm{db}$ (Based on 3 to $180 \mathrm{~Hz}, 42 \mathrm{db}$ preamp gain, $600 \mathrm{ohm}$ input, notch and lowcut filters out, alias filter set to $180 \mathrm{~Hz}$ )

Lower "3 db" Frequency, $1.6 \mathrm{~Hz}+-10 \%$

Upper " $3 \mathrm{db}$ " Frequency, determined by alias filter

$1 \%$

$2 \%$

$0.05 \%$ (with all gains set to minimum, input $=0.226$ Vrms, signal 3 to $1000 \mathrm{~Hz}$ )

$<80 \mathrm{db}, 3$ to $2000 \mathrm{~Hz}$

$\overline{0} .002 \%$

Within a single 8 channel group, $1 / 32$ msec/channel 


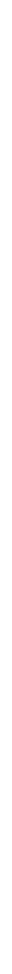


Piledriver Event, Nevada Test site (Area 15)

Data Obtained: 27 July 92

Weather: Slight Breeze, 90F, Sunny

Instrument: Leitz Autolevel B-4, S\# 950260

\begin{tabular}{|c|c|c|c|c|c|}
\hline station & Reading & True & station & Reading & True \\
\hline 101 & $6.44 \mathrm{ft}$ & $-1.38 \mathrm{ft}$ & 125 & 4.79 & 0.27 \\
\hline 102 & 6.40 & -1.34 & 126 & 4.54 & 0.52 \\
\hline 103 & 6.36 & -1.30 & 127 & 4.64 & 0.42 \\
\hline 104 & 6.37 & -1.31 & 128 & 4.73 & 0.33 \\
\hline 105 & 6.30 & -1.24 & 129 & 4.90 & 0.16 \\
\hline 106 & 6.25 & -1.19 & 130 & 5.05 & 0.01 \\
\hline 107 & 6.21 & -1.15 & 131 & 5.10 & -0.04 \\
\hline 108 & 6.22 & -1.16 & 132 & 5.10 & -0.04 \\
\hline 109 & 6.24 & -1.18 & 133 & 4.97 & 0.09 \\
\hline 110 & 6.32 & -1.26 & 134 & 4.92 & 0.14 \\
\hline 111 & 6.35 & -1.29 & 135 & 5.04 & 0.02 \\
\hline 112 & 6.32 & -1.26 & 1.36 & 5.06 & 0.00 \\
\hline 113 & 6.04 & -0.98 & 137 & 5.07 & -0.01 \\
\hline 114 & 5.64 & -0.58 & 138 & 5.00 & 0.06 \\
\hline 115 & 5.30 & -0.24 & 139 & 4.96 & 0.10 \\
\hline 116 & 5.16 & -0.10 & 140 & 5.08 & -0.02 \\
\hline 117 & 4.96 & 0.10 & 141 & 5.08 & -0.02 \\
\hline 118 & 4.89 & 0.17 & 142 & 5.16 & -0.10 \\
\hline 119 & 4.83 & 0.23 & 143 & 5.22 & -0.16 \\
\hline 120 & 4.82 & 0.24 & 144 & 5.17 & -0.11 \\
\hline 121 & 4.85 & 0.21 & 145 & 5.16 & -0.10 \\
\hline 122 & 4.88 & 0.18 & 146 & 4.92 & 0.14 \\
\hline 123 & 4.85 & 0.21 & 147 & 4.62 & 0.44 \\
\hline 124 & 4.96 & 0.10 & 148 & 4.40 & 0.66 \\
\hline SGZ & 5.06 & 0.00 & 149 & 3.95 & 1.11 \\
\hline
\end{tabular}




\begin{tabular}{|c|c|c|c|c|c|}
\hline 150 & 3.46 & 1.60 & 175 & $7.24 / 7.42$ & 4.99 \\
\hline 151 & 2.96 & 2.10 & 176 & 7.40 & 5.01 \\
\hline 152 & 2.39 & 2.67 & 177 & 7.36 & 5.05 \\
\hline 153 & $2.06 / 6.36$ & 3.00 & 178 & 7.28 & 5.13 \\
\hline 154 & 5.93 & 3.43 & 179 & 7.16 & 5.21 \\
\hline 155 & 5.70 & 3.66 & 180 & 7.00 & 5.37 \\
\hline 156 & 5.46 & 3.90 & 181 & 7.06 & 5.31 \\
\hline 157 & 5.19 & 4.17 & 182 & 7.58 & 4.79 \\
\hline 158 & 5.01 & 4.35 & 183 & 6.90 & 5.47 \\
\hline 159 & 4.76 & 4.60 & 184 & 6.62 & 5.75 \\
\hline 160 & 4.56 & 4.80 & 185 & 6.24 & 6.13 \\
\hline 161 & 4.43 & 4.93 & 186 & 6.29 & 6.08 \\
\hline 162 & 4.27 & 5.09 & 187 & 6.00 & 6.37 \\
\hline 163 & 4.18 & 5.18 & 188 & 5.52 & 6.85 \\
\hline 164 & 4.11 & 5.25 & 189 & 5.21 & 7.16 \\
\hline 165 & 4.04 & 5.32 & 190 & 5.04 & 7.33 \\
\hline 166 & 3.96 & 5.40 & 191 & 4.84 & 7.53 \\
\hline 167 & 3.89 & 5.47 & 192 & 4.57 & 7.80 \\
\hline 168 & 3.84 & 5.52 & 193 & 4.28 & 8.09 \\
\hline 169 & 4.02 & 5.34 & 194 & 3.98 & 8.39 \\
\hline 170 & 4.07 & 5.29 & 195 & 3.63 & 8.74 \\
\hline 171 & 4.22 & 5.14 & 196 & 3.32 & 9.05 \\
\hline 172 & $4.26 / 7.13$ & 5.10 & 197 & 3.03 & 9.34 \\
\hline 173 & 7.13 & 5.10 & 198 & 2.67 & 9.70 \\
\hline 174 & 7.18 & 5.05 & & & \\
\hline
\end{tabular}


Appendix 4-

Eavesdropper Processing Deck: Regular Offset Data 


\section{PILEDRVR.DEK}

$>$ >start

*INPF piledrur.kgs

*AUED 100.25011

*EDKL 928

kill 11622

kill 183822

kill 545622

kill 596122

kill 6372124

*EDFM 928

tapr 10

farm 117520

farm 21020

farm 516020

farm 61020

farm 914520

farm 10102044550

farm 111050

farm 1230455506075580

farm 13140204455065570

farm 141060

farm 15160203045550

farm 161602034540

farm 171502070

farm 1816220

farm 1910

farm 281552033540

farm 291030

farm 341792034544550

farm 351552034344250

farm 361040

farm 3713820

farm 381020

farm 3916020310049850

farm 4017020

farm 4119020

farm 4214220

farm 431020

farm 441452035840

farm 451030

farm 4618820

farm 4716820

farm 4817020

farm 491642281228

farm 5017522838268270240

farm 5110240

farm 5217820310249050

farm 53181203040

farm 5418120

farm 5514320

farm 561602034140

farm 571712030 
farm 5814820

farm 5910

farm 621422251225130

farm 6314820120

*EDMT 928

tapr 10

mute 1320034150400

mute 143004305053055600

mute 151002400

mute 183004324553549600

mute 191002400

mute 2113545200

mute 221002400

mute 2860077588800

mute 29500665100700

mute 301002400

mute 3130046890500

mute 322003558545864500

mute 3310020034865400

mute 3650066685700

mute 371002400

mute 382003738746191500

mute 391002400

mute 4020036377400

mute 4130050064158700

mute 4240054351600

mute 431546820030043289500

mute 441002400

mute 45145582003357143855500

mute 461002003366143858500

mute 4720034052400

mute 482003326140060074055800

mute 49300447655006396174360800

mute 501002400

mute 51132782003004345654052600

mute 5210040058095600

mute 5320037310349095500

mute 543000400

mute 612003566545267500

mute 62300400

*SORT 12191

ptrn 5240

pn 1101111241

SHOT

snsn $<1621><1011621>1$

tabl 00

*NMOT 0.5

velf 17017500

*STAK 1

*OUTF pilestak.kgs

$>$ > end 
Appendix 5-

Eavesdropper Processing Deck: Wideangle Data 
WIDEPILE.DEK

$>$ start

*INPF widepile.kgs

*AUED 100.25011

*SORT 12191

ptrn 5240

pn 01101149241

pn 02101172241

pn 03103149241

pn 04103172241

pn 05105149241

pn 06105172241

pn 07107149241

pn 08107172241

pn 09109149241

pn 10109172241

pn 11111149241

pn 12111172241

pn 13113149241

pn 14113172241

pn 15115149241

pn 16115172241

pn 17117149241

pn 18117172241

pn 19119149241

pn 20119172241

pn 21121149241

pn 22121172241

pn 23123149241

pn 24123172241

pn 25125149241

pn 26125172241

SHOT

sn 01101

sn 02101

sn 03103

sn 04103

sn 05105

sn 06105

sn 07107

sn 08107

sn 09109

sn 10109

sn 11111

sn 12111

sn 13113

sn 14113

sn 15115

sn 16115

sn 17117

sn 18117

sn 19119

sn 20119 
sn 21121

sn 22121

sn 23123

sn 24123

sn 25125

sn 26125

tabl 00

*SURF 5000

alvf 5009.7032004900

se 014998.625001 .11

se 024998.625005 .10

se 034998.705001 .11

se 044998.705005 .10

se 054998.765001 .11

se 064998.765005 .10

se 074998.855001 .11

se 084998.855005 .10

se 094998.825001 .11

se 104998.825005 .10

se 114998.715001 .11

se 124998.715005 .10

se 134999.025001 .11

se 144999.025005 .10

se 154999.765001 .11

se 164999.765005 .10

se 175000.105001 .11

se 185000.105005 .10

se 195000.235001 .11

se 205000.235005 .10

se 215000.215001 .11

se 225000.215005 .10

se 235000.215001 .11

se 245000.215005 .10

se 255000.275001 .11

se 265000.275005 .10

*NMOT 0.5

velf 17017500

*STAK 1

*OUTF widestak.kgs

$>$ > end 


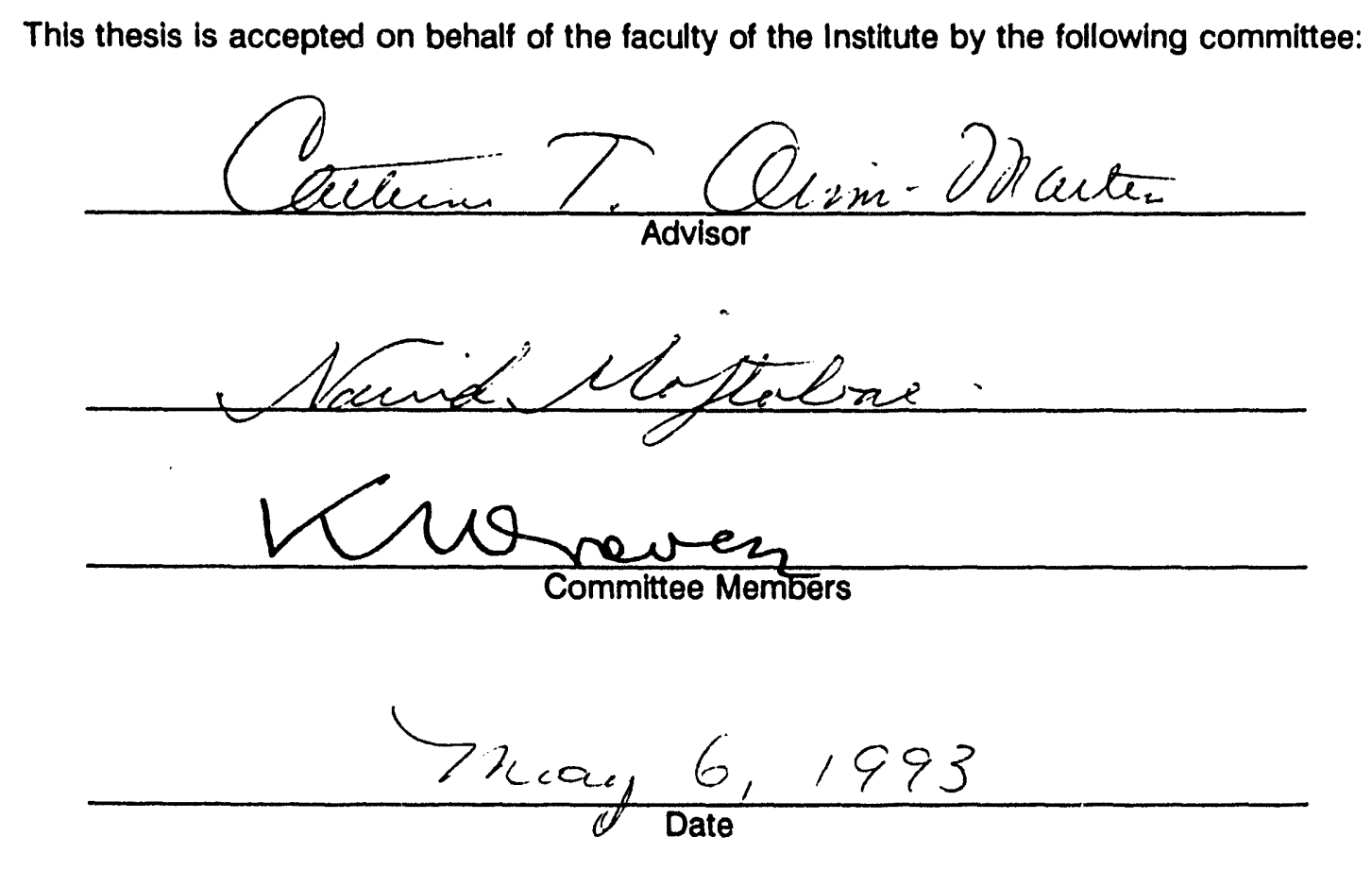



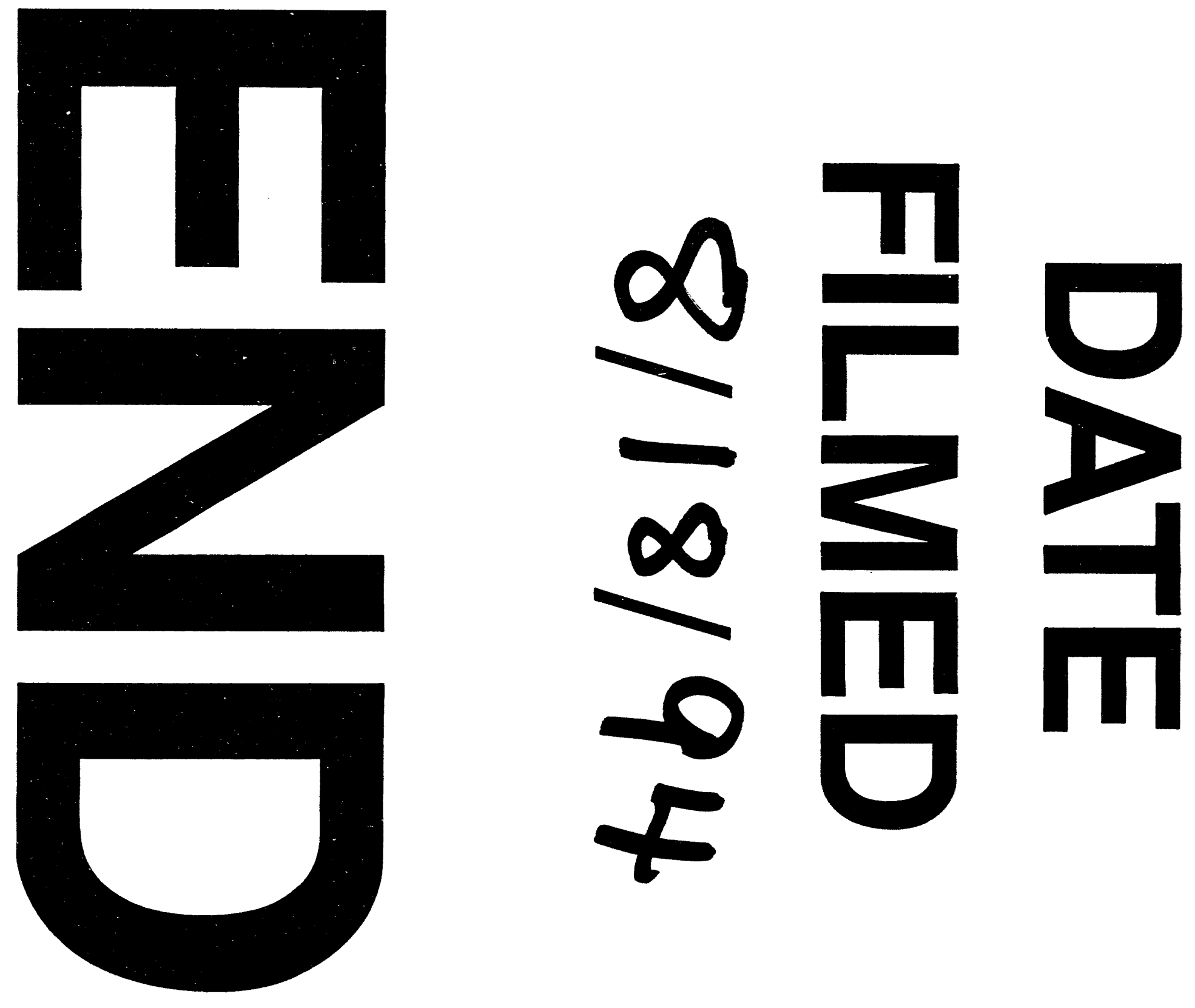

0
8
P 
